\title{
Assessment of Industrial Attitudes Toward \\ Generic Research Needs in Tribology
}

September 1985

Prepared for the U.S. Department of Energy under Contract DE-AC06-76RLO 1830

Pacific Northwest Laboratory Operated for the U.S. Department of Energy by Battelle Memorial Institute 


\title{
DISCLAIMER
}

This report was prepared as an account of work sponsored by an agency of the United States Government. Neither the United States Government nor any agency thereof, nor any of their employees, makes any warranty, express or implied, or assumes any legal liability or responsibility for the accuracy, completeness, or usefulness of any information, apparatus, product, or process disclosed, or represents that its use would not infringe privately owned rights. Reference herein to any specific commercial product, process, or service by trade name, trademark, manufacturer, or otherwise, does not necessarily constitute or imply its endorsement, recommendation, or favoring by the United States Government or any agency thereof. The views and opinions of authors expressed herein do not necessarily state or reflect those of the United States Government or any agency thereof.

\author{
PACIFIC NORTHWEST LABORATORY \\ operated by \\ BATTELLE \\ for the \\ UNITED STATES DEPARTMENT OF ENERGY \\ under Contract DE-AC06-76RLO 1830
}

\begin{tabular}{|c|c|}
\hline \multicolumn{2}{|c|}{ Printed in the United States of America } \\
\hline \multicolumn{2}{|c|}{ Available from } \\
\hline \multirow{2}{*}{\multicolumn{2}{|c|}{$\begin{array}{l}\text { National Technical Information Service } \\
\text { United States Department of Commerce }\end{array}$}} \\
\hline & \\
\hline 5285 & ad \\
\hline \multicolumn{2}{|c|}{ Springfield, Virginia 22161} \\
\hline \multicolumn{2}{|c|}{$\begin{array}{l}\text { NTIS Price Codes } \\
\text { Microfiche A01 }\end{array}$} \\
\hline$N$ & \\
\hline \multicolumn{2}{|c|}{ Printed Copy } \\
\hline & Price \\
\hline Pages & Codes \\
\hline $001-025$ & $\mathrm{~A} 02$ \\
\hline $026-050$ & $A 03$ \\
\hline $051-075$ & $\mathrm{AO4}$ \\
\hline $076-100$ & A05 \\
\hline $101-125$ & AO6 \\
\hline $126-150$ & $A 07$ \\
\hline $151-175$ & $A 06$ \\
\hline $176-200$ & $\mathrm{~A} 09$ \\
\hline $201-225$ & A010 \\
\hline $226-250$ & A011 \\
\hline $251-275$ & A012 \\
\hline $276-300$ & $A 013$ \\
\hline
\end{tabular}


L. B. Sibley

Tribology Consultants Incorporated

M. Zlotnick Consultant to

Tribology Consultants Incorporated

T. M. Levinson

DOE/ECUT Program Manager

September 1985

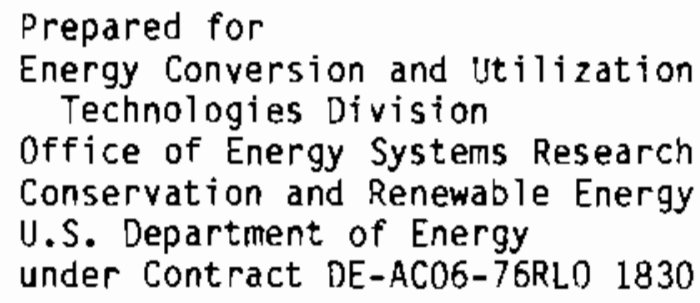




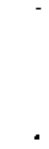


Experts estimate that in 1978 over four quadrillion Btu of energy were lost in the United States because of simple friction and wear--enough energy to supply New York City for an entire year. This translates to a $\$ 20$ billion loss, based on oil prices of about $\$ 30$ per barrel. (a) Because of the enormity of this energy loss, the Energy Conversion and Utilization Technologies (ECUT) Program in the U.S. Department of Energy (DOE) initiated a program in 1983 to study tribology--the science of friction and wear--to learn more about the causes of these energy losses (or tribological "sinks") and how to reduce them.

The ECUT Program itself was started in 1980 to encourage research to improve energy conversion and utilization efficiency. The enormous energy loss in tribological sinks has been targeted by the ECUT program as having significant potential for energy conservation. One goal of the ECUT Tribology Program is to reduce these energy losses by developing improved lubricants and more durable materials.

To support initial Tribology Program planning, ECUT conducted six surveys to gather three types of information about the current tribology probiem in the U.S.:

1. The identification of typical industrial sinks

2. A survey of current U.S. Government tribology projects

3. The identification of tribology R\&D needs based on industry perceptions.

The six ECUT-sponsored surveys are listed in Table ES.1. Each survey is being published as a separate volume with its own summary. This executive summary, which also appears in each of the six volumes, presents an overview of resuits from the six surveys and their implications for energy conservation. The results of these six surveys and their implications for energy conservation are presented in this sumary. These results will be used to support further research planning for the ECUT Tribology Program.
TABLE ES.1. ECUT Surveys Reviewed in this Summary

1. A Review of Tribological Sinks in Six Major Industries. Imhoff, et a]. PNL-5535, Pacific Northwest Laboratory, Richland, Washington.

2. Reduction in Tribological Energy Losses in the Transportation and ETectric Utilities Sectors. Pinkus and Wilcock, Mechanical Technology Incorporated. PNL-5536, Pacific Northwest Laboratory, Richland, Washington.

3. Identification of Tribological Research and Development Needs for Lubrication of Advanced Heat Engines. Fehrenbacher, Technology Assessment and Transfer, Incorporated. PNL-5537, Pacific Northwest Laboratory, Richland, Washington.

4. Energy Conservation Potential of Surface Modification Technologies. Le Khac, OHR, Inc. PNL-5538, Pacific Northwest Laboratory, Richland, Washington.

5. Assessment of Government Tribology Programs. Peterson, Wear Sciences Corporation. PNL-5539, Pacific Northwest Laboratory, Richland, Washington.

6. Assessment of Industrial Attitudes Toward Generic Research Needs in Tribology. Sibley and Zlotnick, Tribology Consultants Incorporated. PNL -5540 , Pacific Northwest Laboratory, Richland, Washington.

IDENTIFYING TYPICAL TRIBOLOGICAL SINKS AND MECHANISIMS

ECUT's first step in collecting information about tribology was to identify significant tribological sinks and mechanisms. This information was needed to focus research on key technological problems. Because the industry, transportation, and utilities sectors account for most of the

(a) Calculations in this summary are based on a $\$ 30$ 1fgure. 
energy consumed in the U.S., ECUT concentrated first on the tribological energy sinks and mechanisms found in these three sectors. The report by Imhoff, et al., describes the most important tribological sinks typically found in industry, and the report by Pinkus and Wilcock describes tribological energy losses in the transportation and utilities sectors. Two specific studies assessed tribological problems in the metalworking industry and in the advanced diesel engine.

To identify areas in which tribology has a significant impact, the authors examined the energy consumed, the fuels used, and the primary products and processes found in the transportation, industrial, and utilities sectors. Once energy losses were identified, their magnitude was estimated. The estimates include both friction losses (direct losses) and material wear losses (indirect losses). The authors also estimated the energy savings potential in each sector and recommended some specific R\&D programs to help achieve these energy savings.

\section{The Industrial Sector}

Tribological energy losses are pervasive throughout industry. Because reviewing all industries and industrial processes in detail would be impossible, the Imhoff, et al . survey, instead chose six representative industries (Mining, Agriculture, Primary Metals, Chemicals/Refining, Pulp and Paper, and Food Processing) that appeared to have the most significant tribological sinks and energy losses. These industries were selected because of their 1) major, nonthermal energy streams (such as machine drives); 2) high material wear rates and friction; 3) significant material transportation/alteration processes; and 4) total energy use.

The study identified important tribological sinks in each selected industry, based on both friction and material wear energy losses and on the tribological mechanisms and materials involved. Figure ES.1 and Table ES. 2 show the key results for each of the six industries.

The first conclusion from this study confirmed earlier claims that losses from material wear are greater than energy losses from friction; the wear losses in five of the industries were found to be more than twice as large as the friction losses. (a) The study also concluded that reducing material wear rates to improve equipment life

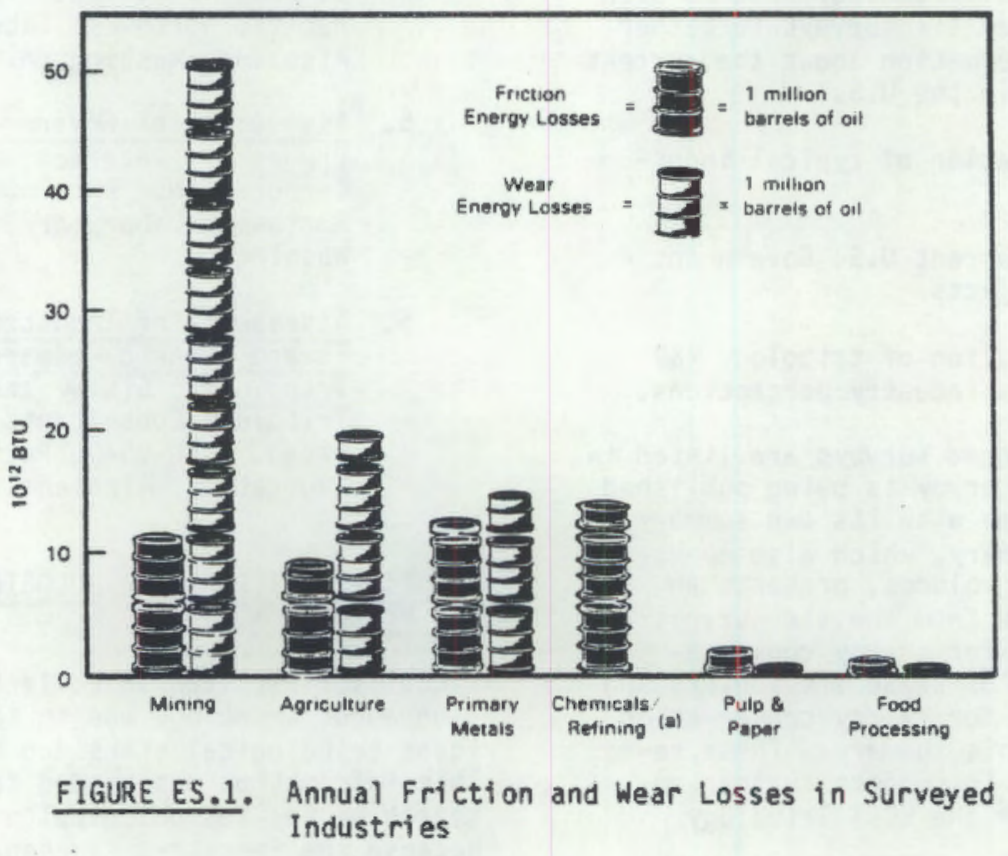

(a) These five industries had estimates of both friction and material wear losses; the sixth, Chemicals/Refining, did not have estimates of wear losses. 
TABLE ES.2. Primary Mechanisms in Friction Energy Losses and Principal Materials Involved in Wear Energy Losses

$\frac{\text { Industry }}{\text { Mining }}$
Agriculture
Primary Metals
Chemicals/Refining

Puip \& Paper

Food Processing

\author{
Mechanisms \\ 3-body Abrasion \\ Friction
3-body Abrasion Friction
Hot Rolling Inefficiencies
Friction, Erosion Abrasion

Friction

Erosion, Abrasion

\section{Materials}

Iron, Steel \& alloys, Alumi num, Rubber

Steel, Rubber, Lubricants

Steel \& alloys

Not studied

Steel \& alloys, ChromiumMolybdenum alloys Grinding stones

Steel alloys and reliability would also significantly improve industrial productivity. The industry representatives interviewed strongly emphasized the positive impacts that tribological research could have on operational productivity.

\section{Tribology in the Metalworking Industry}

In addition to the general review of tribological sinks in industry, ECUT sponsored a more specific study of tribology in the metalworking industry by Le Khac at DHR, Inc. The study estimated the energy conservation potential of using advanced surface modification technologies in this industry. These surface modification technologi es are thermal, chemical, or mechanical treatments that reduce friction and wear at a material's surface without changing its bulk properties. The advanced surface modi fication technologies considered were ion implantation, laser surface hardening, electron beam surface hardening, and wearresistant coating deposition. The author studied 70 percent of the metal-forming and metal-cutting machines used in the United States (except those associated with primary metals processing), identified tribological mechanisms, and estimated friction and wear energy losses. Potential energy savings from using surface-modified tools were also estimated.

The metal-forming machines studied were punches, presses and forges, and the metalcutting machines studied were turning, drilling, miliing, broaching, and sawing machines. Models were developed to estimate friction and wear energy losses and potential savings. The friction losses were estimated by adding friction losses at the motor drive system and at the tool-workpiece interface. Estimates of energy consumption were based on standard operating conditions (known friction coefficients, total working time, etc.) The indirect losses from wear were estimated based on the replacement costs of all metalworking tools used and discarded in one year.

Based on actual experimental or production data, the author estimated that the friction losses in all U.S. mptalworking machines amount to $20.2 \times 10^{12}$ Btu per year, or $\$ 104.5 \mathrm{mllli}$. Of this energy loss, $1.8 \times$ $10^{12}$ Btu per year, or 9\%, could be saved using surface modification technologies to reduce friction. The weas loss was estimated to be $7.7 \times 10^{12}$ Btu per year.(a) Possible energy savings using surface modification technologies to reduce wear could conserve $5.5 \times 10^{12}$ Btu per year, or $71 \%$.

Finally, the author estimated that tribological energy losses in all U, S. metalworking machines total $27.9 \times 10^{12} \mathrm{Btu}$, equivalent to $4.8 \mathrm{million}$ barreis of of 1 or $\$ 144 \mathrm{million}$ annually. More than a quarter of this loss could be saved using surface modification technologies to reduce friction and wear. These results are shown in Figure ES.2.

(a) Using 19.2 milition Btu per ton as the embodied energy in steels. 


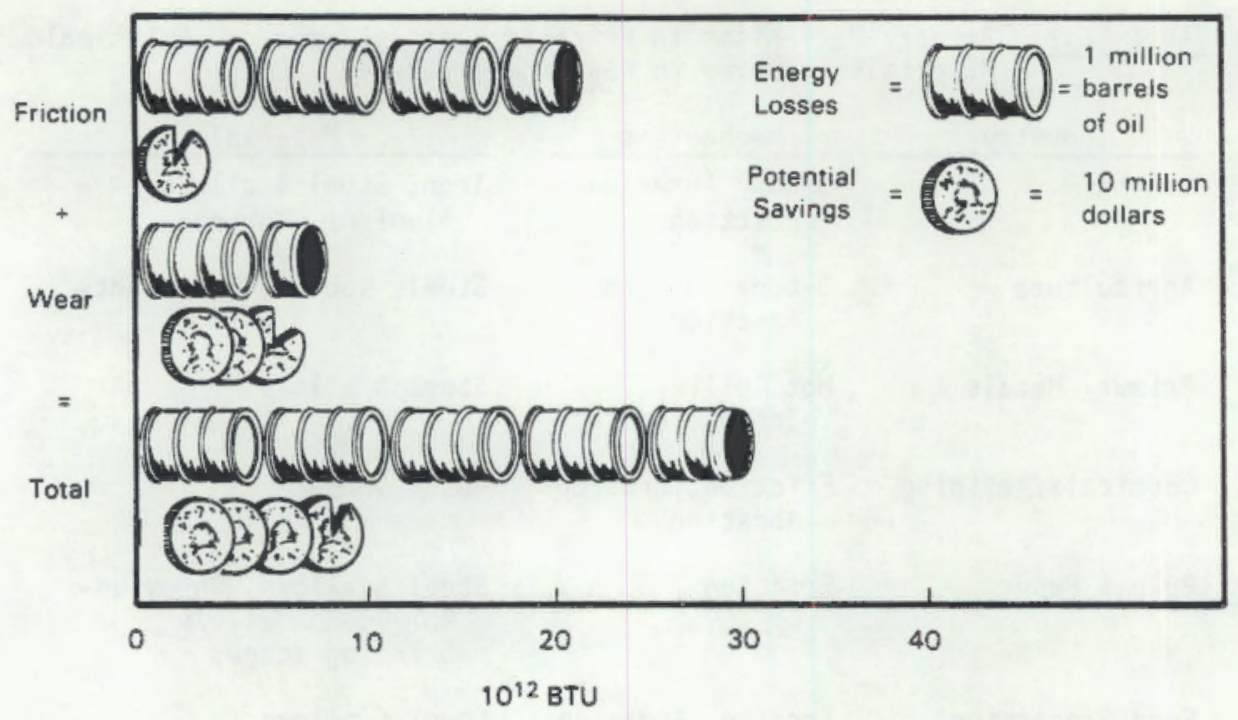

FIGURE ES.2. Annual Friction and Wear Energy Losses in the Metalworking Industry, and Potential Savings from Surface Modification Technologies

\section{The Transportation Sector}

The transportation sector is important both in terms of its energy consumption (26\% of tota] U.S. annual energy consumption, or $19 \times 10^{15} \mathrm{Btu}$, equivalent to $\$ 98$ billion), and because of the high level of tribological losses. The Pinkus and Wilcock study primarily focused on the highway fleets (passenger cars, buses and trucks), which consume $77 \%$ of the total energy used in the transportation sector. The survey primarily addressed the conventional otto cycle engine. However, other concepts were al so considered, such as the adiabatic diesel, the gas turbine, and the Stirling engine; in addition, the Fehrenbacher report evaluated tribological activity in advanced diesel engi nes.

Figure ES. 3 shows the principal automotive tribological sinks and the estimated energy savings. The principal automotive energy sinks are caused by the mechanical inefficiency of the engines and drive trains; most of the energy losses are due to friction.

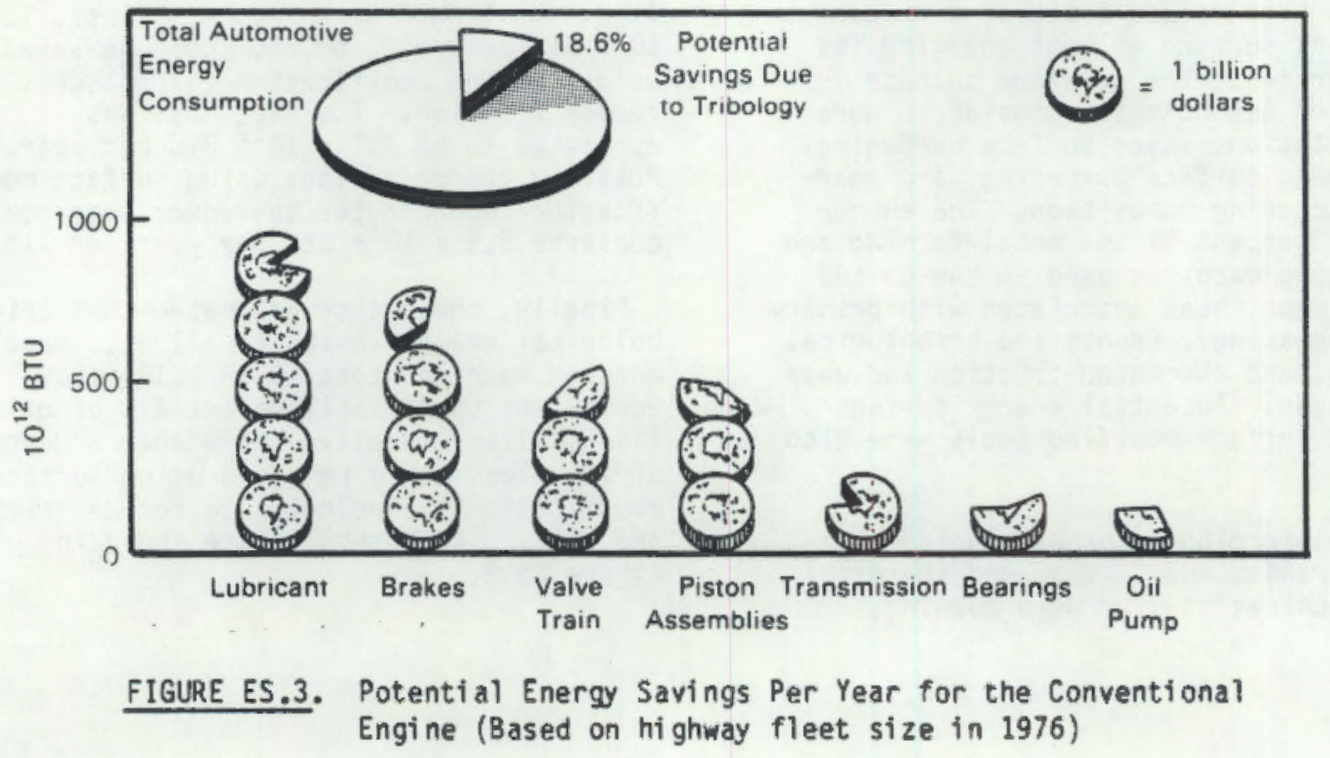


The survey by Pinkus and Wilcock revealed several tribological areas of particular concern for conventional engines, such as the piston ring assembly and the long-range effect of low-viscosity oil on engine wear. As shown in Figure ES.3, tribological improvements could save $18.6 \%$ of the total annual energy consumed by automobiles, or $\$ 14.3$ billion.

Research on conventional engines often applies to unconventional engines as well. Except for the adiabatic diesel, the energy savings possible from tribological improvements to unconventional engines are less significant than those of the conventional otto cycle engine. The major problems in unconventional engines are related to hightemperature tribological problems. Introducing adiabatic and mi nimum friction engines into the bus and truck fleets of the U.S. could save up to $2.9 \%$ of total U.S. energy consumption.

This survey also revealed the difficulties with devising adequate performance tests to quantify energy losses and evaluate new designs and products. Laboratory tests that accurately reflect real-world conditions are badly needed. The ability to test entire systems is vital, since tribological energy losses are often caused by complex interactions between all the components of a system.

\section{Advanced Diesel Engines}

Because of the great potential for energy savings, the ECUT study by Fehrenbacher examined the lubrication of advanced diesel engines in detail. The efficiency of these engines could be improved by about $10 \%$; however, higher operating temperatures $\left(1000^{\circ} \mathrm{F}\right.$ and higher in the upper cylinder area) are required to reach this greater efficiency. As a result, the primary development challenge for these engines concerns friction, wear, and lubrication of the upper cylinder region. In fact, tribological advancements in these areas are essential if diesel engine performance and durability goals are to be reached. This study assessed these vital tribological concerns in both current and future technologies and recommended tribology R\&D topics for further advanced engine development.

Both the mechanical design of the upper cylinder and the chemical effects of lubricants and fuel determine the friction and wear characteristics of the upper cylinder region. These two factors interact in a complex and sometimes synergistic manner. The geometry of the piston, piston ring, and cylinder di rectly affect the rate and nature of deposit formation, oil consumption, and friction. Efforts have been made to optimize the upper cylinder geometry in current diesel engine technology; this will also be a critical area in future developments. However, problems with upper cylinder deposits, bore polishing, and oil consumption still exist. This study indicates that these problems are caused by the chemical interactions between upper cylinder materials, oil degradation products, and fuel combustion by-products. Therefore, lubricants, oil degradation rates, and mechanisms will continue to be important research areas.

Although a great deal of research has been conducted on liquid lubricants, in most cases the lubricants have been tested without considering the tribological factors specific to the upper cylinder. Since the lubricants interact with the materials and environment of the upper cylinder, they must be developed and tested under similar conditions.

The ECUT study also pointed out that future advanced engine concepts will require ceramic upper cylinder materials able to withstand the higher operating temperatures. New lubricants will have to be developed, and solid lubricants are likely to play a major role. A major research effort will be needed in this area; again, the research must be conducted on a total system basis to be most effective.

The study concluded that many problems with current diesel engines will continue to exist in advanced diesel engines. Tribological problems in the upper cylinder region will be most critical in terms of engine performance and wear. Lubricant R\&D is still a major research area in current technology, but total system materials and design considerations should be emphasized. Advanced diesel concepts will require new design approaches, but the tribology of the upper cylinder region will still be critical and may even be the limiting factor in achieving higher engine efficiencies. Extensive materials R\&D will be required for advanced designs as well, especially in ceramics, ceramic composites and solid lubricants.

\section{The Utilities Sector}

The utilities sector was also reviewed for significant tribology sinks. This sector accounts for roughly $28 \%$ of total U.S. energy consumption. ECUT's review revealed that tribological improvements in efficiency and reliability could save 2.3\% of the total energy annually consumed by utilities, or about $\$ 2.5$ billion. As in the transportation sector, efficiency is a major factor. 
However, reliability (especially in generating units) is just as important for energy conservation.

The data used in these studies were primarily for the utilities' power plants. The average power plant operates at an efficiency (output energy/input energy) between 30 and $40 \%$. Mechanical losses account for $17-26 \%$ of the total energy used. Reliability problems that lead to generator shutdown require using standby equipment, which generally has less efficient fuel consumption. This causes losses both in terms of fuel economy, and revenue and labor costs. Tribological problems are estimated to cause as much as $5 \%$ of the reliability problems that require shutdown. Furthermore, tribology-caused shutdowns increase with the size of the power generating unit.

The ECUT survey found several tribological areas with significant energy savings potential, including gas path leakage, seals, and bearings on both the main turbine generator and on the various accessories. Different forms of bearing and lubricant problems (contaminated oils, pump problems, etc.) and vibrations are the leading causes of the plant shutdowns.

Figure ES.4 summarizes potential savings from improving tribological problems in the electric utilities. For accessories, the major concern is sealing problems with feedwater pumps. Friction and wear are implicated in much of the seal and bearing 1osses. The major problems identified in this study will require research on lubrication theory and advanced materials and coatings developments.

\section{CURRENT U.S. GOVERNMENT PROGRAMS}

The second part of ECUT's information collecting efforts involved identifying tribology R\&D currently being sponsored or conducted by the U.S. Government. This information was needed to avoid duplicating existing research and to locate those areas that need more research support. The Peterson study identified 215 current projects sponsored by 21 different government organizations. The study classified these projects by subject, objective, energy conservation relevance, type of research, phenomena and variables being investigated, materials, and applications. The principal government sponsors include the Department of Defense (DOD), the National Aeronautics and Space Administration (NASA), National Science Foundation (NSF), National Bureau of Standards (NBS), and DOE.

The study located these tribology projects initially by using information from literature searches. Data bases used included the Smithsonian Science Information Exchange, the Defense Technical Information Center's Research and Technology Work Unit Information System, and the Materials Science Abstracts of the National Technical Information Service (NTIS). The study located a

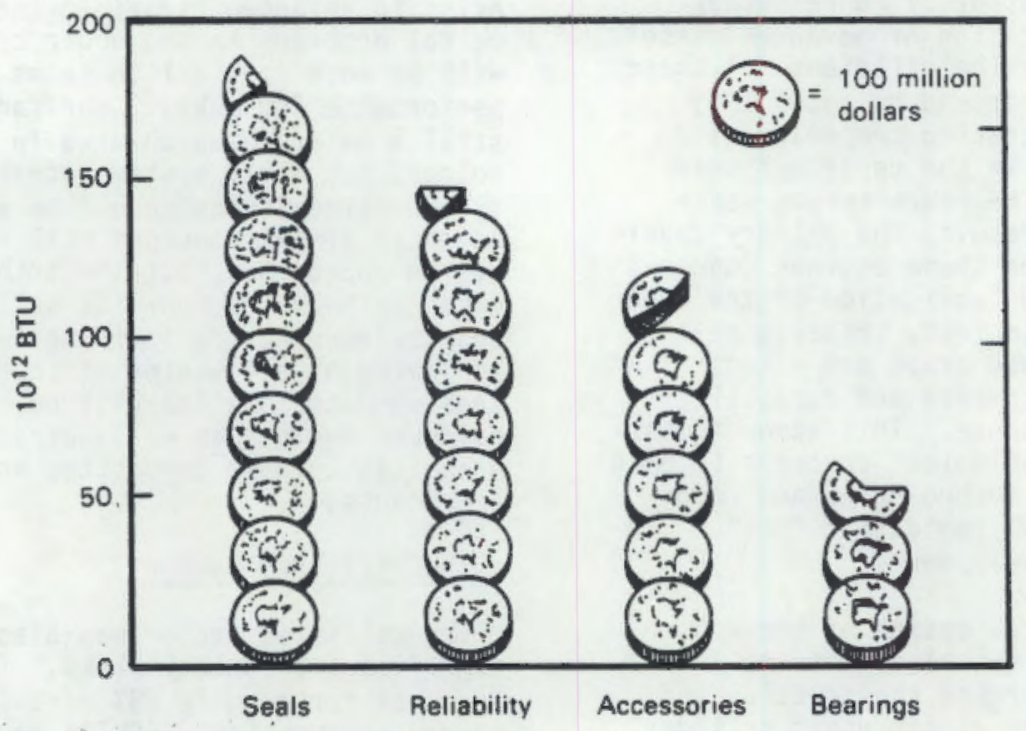

FIGURE ES.4. Potential Energy Savings for the Utilities (Based on estimates of installed capacity in 1983 and on an energy cost of $\$ 30$ per barrel.) 
total of 640 government-sponsored projects covering the fiscal years 1978-1983. These organizations were then contacted by mail, followed by visits and/or phone discussion. Of the original 640 projects, 215 were found to be current. A detailed description of each project is included in the report.

According to this study, until several years ago tribology research emphasized component development, fluid film and elastohydrodynamic lubrication, and concentrated contacts. Since then the emphasis has shifted dramatically, and research efforts now concentrate on lubricants, mate$r i$ als and coatings, and friction and wear mechanisms. There is still considerable interest in rolling contact bearings and seals, as well as in early failure detection in maintenance technology.

The study aiso concluded that most current tribology research is related to $D 00$ objectives of longer life, low maintenance/ failure-free machinery, and the basic understanding of friction, wear, materials, and coatings. High-temperature lubrication also continues to be a major objective in tribology research; the effects of new materials and solid lubricants on current temperature limitations are also being studied. Coatings are receiving the most attention in general materials development. Figure ES.5 shows a breakdown of the materials considered in the 215 projects.

The author also concluded that current programs generally do not emphasize energy or materials conservation. Design predictability and composite materials are other areas that are receiving little attention. Finally, the study concluded that current
U.S. Government high-temperature lubrication work is the most applicable to energy conservation goals.

INDUSTRY PERCEPTIONS OF GENER IC RESEARCH NEEUS IN TRIBOLOGY

Because transferring information to industries is a major part of the ECUT program, ECUT conducted a survey of industry perspectives on tribology R8D needs. This survey, conducted by Sibley and Zlotnick, involved interviewing industry contacts to discover what research results are needed.

The authors held in-depth discussions with engineers and managers from 27 companies. These companies were chosen by defining different tribological categories (such as transportation, power plants, seals, gears, aerospace, etc.). At least one company was then selected for each category, and two or three were chosen for categories that are particularly important to the ECUT program. The purpose of this study was not to produce statistically significant findings, but rather to represent many different viewpoints and a variety of interests.

The authors' main emphasis was on determining the engineering limitations imposed by tribology considerations. They also tried to determine the type and funding level of current generic tribology R\&D in each company, al though only pon-proprietary information was available. (a)

Based on the levels of generic tribology R\&D in the 27 individual companies, the authors then estimated total tribology R\&D in each industrial segment. Although this approach is obviously limited, reasonably

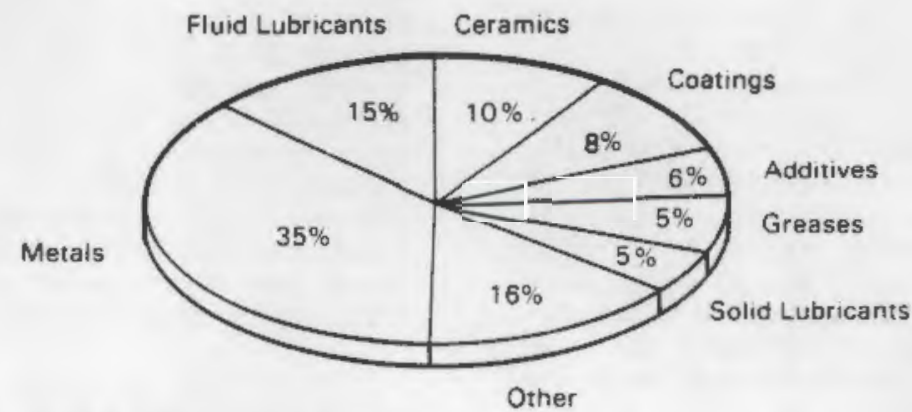

FIGURE ES.5. Materials Under Consideration in the 215 Current Government-Sponsored Tribology Projects

(a) "Generic" R\&D in this case is basic research that is not directed toward a specific end use or product. 
TABLE ES.3. Estimate of Generic Tribology R\&D and Total R\&D Budget for Representative Industries (In \$M)

\begin{tabular}{|c|c|c|c|}
\hline Classification & Company & $\begin{array}{l}\text { Total } \\
\text { R\&D(a) } \\
\end{array}$ & $\begin{array}{c}\text { Generic } \\
\text { Tribology R\&D (b) }\end{array}$ \\
\hline Liquid Lubricants & Mobi 1 & 188 & 1 \\
\hline Transportation & Ford & 1764 & 1 \\
\hline Aerospace & Pratt \& Whitney & 835 & 0 \\
\hline Powerplants & Caterpillar & 234 & 0 \\
\hline Seals & Crane & 10 & $<1$ \\
\hline Rolling Elements & TRW & 109 & $>0$ \\
\hline Gears & Eaton & 100 & $>0$ \\
\hline Sliding Bearings & Tribon & 0 & $>0$ \\
\hline Filters & Pall & 7 & 0 \\
\hline Small Mechanical & Xerox & 565 & $>0$ \\
\hline Cerami cs & Norton & .26 & $<1$ \\
\hline Coatings & Uni on Carbide & 240 & $<1$ \\
\hline \multirow[t]{2}{*}{ Forming } & Bethlehem & 46 & $\leq 1$ \\
\hline & & 4124 & 6 \\
\hline
\end{tabular}

(a) From the report to the Securities and Exchange Commission for 1982. (Source: "Business Week," June 20, 1983.)

(b) Based on discussions with research staff and referring to only company-funded generic tribology R\&D.

accurate estimates were developed of the amounts of generic tribology $R \& D$ being conducted in each of the industrial segments. The results for the individual companies are sumarized in Table ES.3.

These authors concluded that industry funds only a very limited amount of generic tribology research. Some 'hidden' generic R\&D is incorporated into the companies' design manuals, but much of this information is proprietary. As illustrated in

Table ES.3, some industry segments have little or no generic tribology R\&D. Trtbology research efforts are often too small to be likely to improve the state-of-theart; ceramics is an example of an area in which the funding levels are too small to promote significant advances, although industry has expressed considerable interest in this area. However, the liquid lubricant research budget in the transportation industries is substantial.

The industry representatives expressed interest in the ECUT Tribology Program, and also in obtaining a fundamental physical understanding of tribological mechanisms. The industry contacts also requested more effective presentations of research results, especially results in form that design and development engineers could readily use.
Another industry concern involved developing more realistic laboratory tests and more rational performance standards.

\section{CONCLUSIONS}

The six ECUT surveys summarized here were conducted to provide an overview of the major tribological sinks and the current state of U.S. tribology research. Although much of this preliminary ECUT work involved general surveys and samplings, the overall picture is consistent and reveals areas of major concern. The findings in the general surveys have been largely substantiated by the two focused studies on metalworking industries and the advanced diesel engine. These results are being used to support ECUT Tribology Program planning.

These surveys describe the current status of U.S. tribology R\&D in 1984; the findings wit 11 be updated as necessary. Much of the information is necessarily somewhat speculative and theoretical, and many of the general findings have not yet been fully corroborated. This is due in part to the lack of previous research; improving this initial information should be an important goal of current research. In particular, identifying tribological mechanisms should 
be emphasized in order to define specific research projects. Further discussion th industry representatives is also needed.

The five key results from these ECUT studies are listed below:

1. Advanced tribo-materials, coatings, and lubricants must be developed to further improve energy efficiency. Although tribological improvements can be made with the current technology, new and innovative materiais and designs (such as the advanced diesel engine) are needed to significantly increase energy efficiency.

2. Tribological mechanisms that shorten equipment $11 \mathrm{fe}$ and cause excesstve downtlime and repair should be identiffed and studied. Inttial research shows that these indl rect energy losses from materlal wear are often greater than the df rect energy losses from fitition. In addition to the energy consiervation impacts, reducing these losses could also significant ly improve industrial productivity.

3. Generic tribological research will affect all three major sectors, since sinilar tribological mechanisms are found in many different processes. Although the transportation sector has the largest tribological energy loss and the greatest potential for energy savings, there is significant energy savings potential in all sectors. Thus research results must be effectively transferred to all sectors.

4. Mearlingful performance tests and standaris must be developed so that new designs and products can be accurately eva uated. Laboratory tests that accurately reflect real-world conditions are badly needed. Total system testing is vital, since tribological energy losses are often caused by complex interactions between all the components of is system.
5. Continuing communication with industry is critical to ensure that industry research needs are addressed and that the results are adequately transferred.

These results supported the development of the ECUT Trtbology Program plan for 1985. The research program is divided into two parts. The Mechanisms component includes such areas as advanced tribo-naterials R\&D, identifying and characterizing tribological mechanisms, and developing performance test requi rements. Projects in this area include developing new tribological materials, and modeling and experimental efforts to determil ne physical and chemical interactions and processes in tribological systems. Liquid and solid lubricants, tribological coatings and surface modifications, and ceramic and cemet matertals are specific topics to be considered. The Mechanisms area also includes efforts to develop novel characterlzation and testing procedures and diagnostic tools and equipment to assess the performance of tribological systems.

The second part of the research program, Design, includes such topics as design and reliability modeling of components, systems, and system assemblies. Industry is di rectly involved in these projects. The Design area will also establish a data center to gather and dissemi nate information on tribology. These projects concentrate on generic tribology R\&D, including energy losses from material wear.

Clearly, tribology research can have major impact on energy use and conservation in the U.S. Much of the needed research identified in these studies is innovative and high-risk, which makes tribology a vital and appropriate area for ECUT support. Thus the ECUT Tribology Program, with industry participation and cooperation, will continue 1 ts efforts to reduce the enormous energy losses caused by frlction and wear. 

EXECUTIVE SUMMARY FOR THE TRIBOLOGY SERIES $\ldots \ldots \ldots \ldots \ldots \ldots \ldots \ldots \ldots \ldots$ i $i$

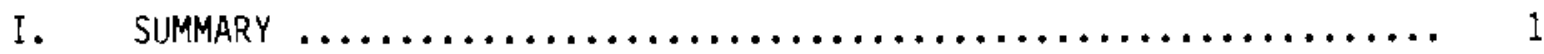

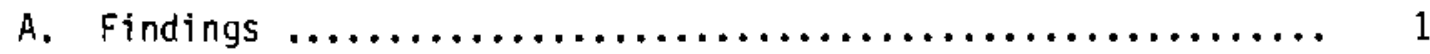

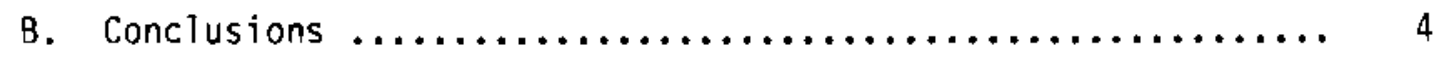

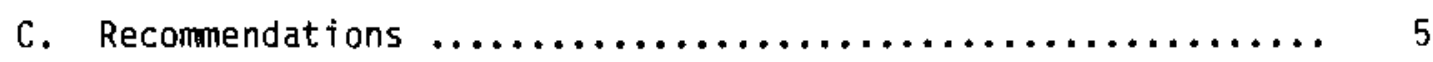

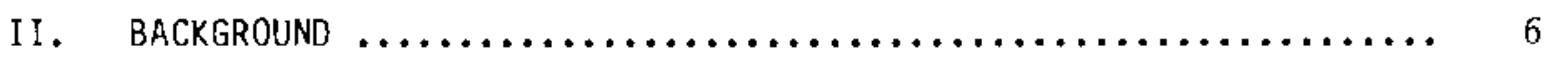

III. APPROACH $\ldots \ldots \ldots \ldots \ldots \ldots \ldots \ldots \ldots \ldots \ldots \ldots \ldots \ldots \ldots \ldots \ldots \ldots \ldots \ldots$

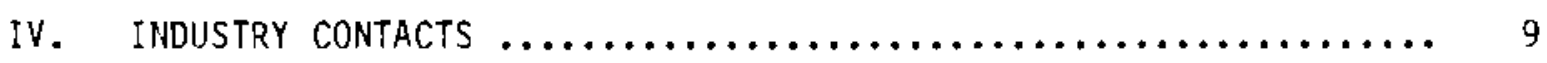

V. INDUSTRY APPRDACH TO GENERIC TRIBOLOGY R\&D $\ldots \ldots \ldots \ldots \ldots \ldots \ldots \ldots . \ldots \ldots$

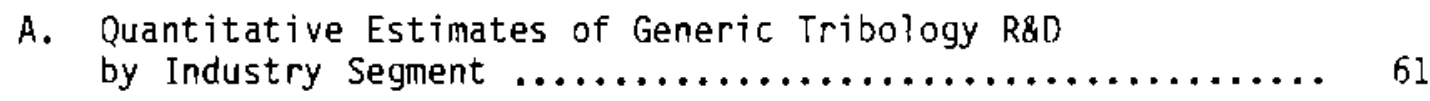

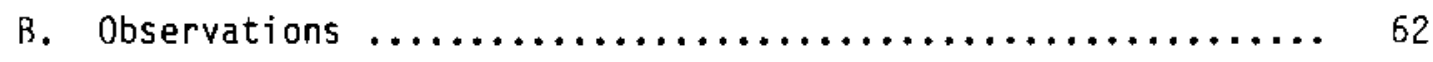

VI. PROGRAMMING GENERIC TRIBOLOGY RESEARCH TO MEET
REOUIREMENTS OF INDUSTRY $\ldots \ldots \ldots \ldots \ldots \ldots \ldots \ldots \ldots$

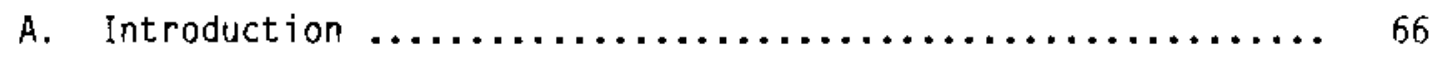

B. Applications of an Integrated Generic Research Package ..... 69

C. Elements of an Integrated Generic Research Package ....... 72

D. Relating Laboratory Characterization and Testing

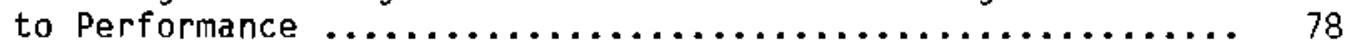

VII. COORDINATION AND COOPERATION IN GENERIC RESEARCH

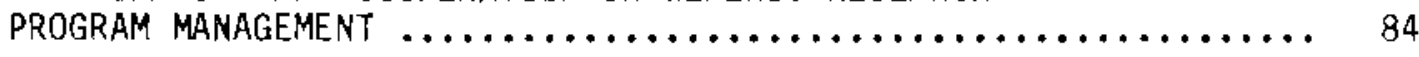




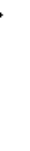


I. SUMMARY

A. Findings:

1. Generic Tribology Research Funded by Industry is Very Limited

Based on extended discussions during visics with 27 companies representing 13 different parts of the cribology industry (such as bearings, Lubricancs, coatings, powerplants), it is apparent that only a tiny fraction of the large sums publicly reported as R\&D expendicures by industry are used to fund generic tribology research. (The "tribology industry" is defined for the purposes of this assessment in Section III.) For example, of the greater than $\$ 2$ B expendi:ures reported for R\&D in che Lubricants sector for 1982, the estimated total for generic tribology research was $\$ 12 \mathrm{M}$. This was the largest expenditure in any sector of the tribology industry and one-chird of the total of $\$ 36 \%$. In the automotive industry out of a reported expenditure of $\$ 4 \mathrm{~B}$, the estimated generic tribology research was $\$ 3 \mathrm{M}$. In some segments of che tribology industry, for example coac1ngs and filters, there were no expendicures on generic research.

Where there was substantial funding by industry, supplemented in some cases by government funds, there was no focusing or coordination of prograns in ways that would foster ECUT goals. That is, there was little tendency to improve the state of the art of the tribology industry through Long-term investment in generic R\&D in ways that would foscer innovation and productivity of energy conservation technology. Expenditures were oriented to development of specific commercial and military products, or to basic research focused on unspecified far term resulcs, although useful spin of $f$ of military developments inro commercial fields sometimes occurs.

\section{Widespread Interest in ECUT Generic Tribology Research Programs}

\section{a. Participation in ECUT Program Planning}

Wich only one, somewhat amblvalent, exception, an invitation to parcicipate in the planning and review of ECUT programs will be welcomed. In some cases the willingness co attend planning and review meetings was unconditional, and in others contingent on the specific techntcal areas.

\section{b. Need to Make Existing Research Results Available}

There was a broad consensus in the companies visited that existing research results were not always made easily accessible to potential users in industry. The implication was chac industry might benefit moce if a larger fraction of the funds were devoted co putring the research results inco a form design and development englneers could more readily apply. The need for a more effective presentation of research results was expressed wich greater urgency at the smaller companies, but there seemed co be a broad consensus on the need Eor improvement. 
Existing methods of presentation are clearly limited. For example, the "ASME Wear Control Handbook", though readily available at most of the companies visited, received only limited use. This suggests that the required emphasis is not only on improving physical access to information on tribology, but on integrating research results into packages more readily useable to engineers.

\section{c. Interest in Fundamental Tribology Mechanisms for Improved Design Predictions}

There was a general interest $\rightarrow$ usually expressed with greater emphasis at the more technically sophisticated organizations -- in fundamental physical understanding of tribological mechanisms, the phenomena that occur at the interface between two solid surfaces in relative motion. This seemed to be based on a strong belief that the understanding would help engineers carry out their function and apply their tribological knowledge more effectively in design predictions.

\section{d. Relating Laboratory Testing to Performance}

There was a broad range of interest in the development of technology that would provide better methods of relating laboratory characterization and tests to performance in the field. Liquid lubricant manufacturers were concerned with testing lubricants and additives, powerplant manufacturers were concerned with metal surfaces resulting from varying forming and finishing processes, and ceramics producers were concerned with quality control and non-destructive evaluation. These interests were shared over other segments of industry.

It is also apparent that the various testing activities were coupled. For example, the characterization of Lubricants in terms of their performance could not be carried out effectively without some reference to the surfaces on which the lubricants were being tested. There is also some redundancy in the requirements for characterizing ceramic and metal surfaces, although there are also differences.

There may also be substantial effects on conservation from improved lubricant testing. Government involvement may be useful to validace claims that friction reduction through the use of Lubricant additives will not necessarily affect durability adversely. Very significant fuel conservation might result from the greater use of additives to reduce friction. The improved cesting technology would also have significant benefits on technical innovation and productivity by expediting the evaluation of new materials and processes.

\section{e. Interest in Engineering Ceram1cs is Growing}

Interest in the use of ceramics appeared to be increas1ng. This was evident in automotive and aerospace segments, outside the powerplant and ceramics programs related to che adlabatic diesel. Applications included cam followers and bearings as well as cylinder liners. There were some claims, but little evidence, that production of durable parts by means other than conventional hor pressing had been developed, and that economical sintering to near net 
shape was possible. Nevertheless, observations made in this assessment tend to confirm press reports that engineering ceramics will develop into a nulci-billion dollar industry in the near future.

f. Widespread Interest by Industry in Cooperative R\&D

Inquiries at the companies vistted disclosed that many would be willing to participace in cooperacive R\&D programs that met their needs. Some have already supported cooperative programs in speciflc areas. This includes zunding of technical work out of the house as well as contributions in kind. 
B. Conciusions:

1. Need for Planiing an Integrated Package of Generic Research

In response to the findings summarized above, Section VI suggests an approach for programming generic tribology research to meet requirements of industry. The essential characteristic of the plan is that it produce an integrated program responsive to the needs of the USERS of research results. These users' needs are significantly different from the needs of the PRODLCERS of research results, which have tended to determine research plans in the past.

An integrated program focuses on one or more specific applications, empirical design, mathematical modelling, or laboratory characterization and resting. It incorporates research on the component scale of phenomena, e.g. a bearing or gear; the macroscopic scale, representing a small surface segment of a component; and the microscopic or atomic/molecular scale. Coupling of theoretical and experimental analysis is required at alI scales. Section VI defines these concepts more precisely, and emphasizes that the research will not produce a useable result for the engineer in industry unless a $\perp$ of these aspects are somehow represented in an integrated package.

Specific technical issues have been used to illustrate these points. One that arises persistently is the coupling between the chemical environment and the tribological phenomena. The coupling impinges on various important problems, including the predfction of lubricated wear, che replenishment of oxides that are critical in solid lubrication for ceramics, and the behavior of lubricant additives in an engine.

\section{Specific Applications and Progran Issues Defined}

Two prograns that follow the foregoing guidelines would relate laboratory characterization and testing to perfomance in two areas, liquid Lubricants (Section VI D 1) and ceramics (Section VI D 2). Innovation and responsiveness to markets in developing and designing new products depends on economical and reliable ways to characterize new or existing materials and components in the laboratory so that designers can use them in new and different ways. This requires development of testing technology and rational standards.

In liquid lubricants this technology has not incorporated consideration of coupling with the chemical environment, and affords an opportunity to coordinate research in a rational way through an incegrated effort. Closely related issues, including scuffing and load capacity prediccion, prediction of Lubricated wear, filtracion, and surface characterization, are subsumed. The benefits are widespread, the most important for ECUT being in the potential for more widespread use of lubricant additives to conserve fuel through reduced friction.

In ceramics, the program is motivated by the opportunity to give much needed aid for American industry in competing with Japan for what is projected to be an immense market. Ceranics rechnology shows a great deal of promise for fostering conservation of fuels by allowing operation at higher temperatures and the use of more compact, high-perfomance machines. Wuch new engineering 
information has to be developed quickly before engineering ceramics becone commercially viable. The extensive practical background accumulated in the use of oil lubricated metals is no longer applicable; and the ceramic industry will not wait another hundred years until it is reproduced. There is no sound alternative to the rational approach of generic research.

\section{Coordination and Cooperation Required with Government and Industry}

The nature of the programs described above require thac ECUT coordinate with other goverment and industry research efforts so that it can use the relevant research results in an Incegraced program geared to both industry's and ECUT's objectives. Opportunities exist for gleanfng results that are applicable to the near term from programs designed for the far term by DOE/OER, NSF, and DARPA.

Similarly, it is likely that generic results can be extracted from relevant government sponsored hardware programs. It is now well known that government sponsored programs to produce commercial products are unlikely to be frufteul, and that the best way for government sponsored technical programs to benefit tndustry in the near term is through generic research. Cooperative funding by industry should also be sought for these integrated programs. Industry has auch to gain by cooperacing with ECUT in such an effort.

For ECUT, working with industry in a cooperative program has three key advantages: Firstly, since industry is investing its own resources, there is direct evidence of the importance and relevance of the program. Secondly, the addition of resources provided by industry permit ECUT to develop a fully integrated generic research program on a limited budget. Finally, cooperating on a program to produce 1nformation for fts own use, will help motivate industry to jarticipate more effectively in the coordination and direction that is required to make the producer of research results responsive to the users needs. Discussions carried out in the course of this assessment indicate that industry would welcome an initiacive fostering cooperation. ECUT support of such an initiative might be very fruitful.

\section{Recommendations:}

It is recommended that ECUT begin to implement the programs suggested by the findings of this assessuent, and outlined in the conclusions above, using its resources in-house, and in the national laboratories, supplemented by contractor support. 


\section{BACKGROUND}

The current version of the ASME "Strategy for Energy Conservation Through: Tribology" has developed an agenda for R\&D. The underlying philosophy is that government support of R\&D can accelerate development of technology designed to reduce the use of scarce fuels. Studies by Batcelle, Argonne and other groups have tended to support this approach.

Since the opportunities for R\&D are so broad and the funds available are so restricted, a substantial effort has been made by the ASME and other groups, in and out of the government, to set priorities. The weighting factors used by ECUT in assessing these priorities have included primarily:

Potential reduction in fuel consumption if the $R \& D$ is successful.

Technical risk or likelihood that the R\&D will be successful.

Likelihood that the private sector will carry out whatever R\&D is needed without government support.

This assessment of priorities has started, appropriately enough, from an evaluation of the public sector needs. The nexc scep has been to determine what research results are needed by engineers who are developing products designed to satisfy the public sector needs for conservacion technology. That is, the purpose of the research sponsored by ECUT is to satisfy the need for information of these engineers. They are the users of the research results produced under ECUT sponsorship.

There has been a consistent effort to get inputs to the planning from the "users" of research results, but their input into ECUT planning of generic tribology research has been much less than the input fron those who are actively engaged in carrying out research. That is, the primary inputs have come from what might be called the "producers" of research results, rather than "users". To a limited extent, the same person may play one role or the other at different times, but the roles themselves are distinctive. Section VI A points out in some detail that the interests of research producers are complementary to the interests of the users of research results, but that these interests also differ in some important respects.

The primary objective for chis assessment, then, was to obtain more information about the needs of development engineers for results of generic research in tribology; that is about the "users'" needs. The primary approach has been to go directly to them and ask what research results are most urgently needed by industry. Another aspect of the question about what research results are needed, is what are not needed because they are already being produced in-house or are otherwise avallable. 


\section{APPROACH}

The basic approach for getting industry's views on what R\&D results it needs was to have discussions in-depth, on a technical level, with engineers and managers in 1ndustry. For that purpose, during the course of this assessment, the authors met with representatives of 27 companies engaged in the production of equipment that depends on tribological factors.

These companies are lisced in Table $V-l$. They represent different categories of participants in the tribology 1ndustry. The categories were defined in an effort to develop a rational sampling strategy, and are based on the postulated structure for the "tribology induscry" shown in Eigure III-1. An effort was made to include at least one representative of each category and, in areas believed to be of greatest importance to ECUT, two or three. This was obviously not adequate to produce statistically significant results; but :he auchors belleve chat an heuristlc appreciation of the different points of view, and the variety of interests in the tribology 1ndustry, was achievable.

The meet:ngs, each of which lasted from two to four hours, began with an introductory briefing by the authors. This included descriptions of key ECUT activities and accomplishuents, ECUT plans and objectives; and a statement of :he reasons for the visit, that is to obtain planning information and support cor ECUT. A technical presentation of some results of ECUT sponsored research and related copics concluded the first stage of the meeting. The purpose of the authors' briefing was to have the meeting be an exchange of views, rather than simply an interview to extract information from industry.

The second stage of the meeting began with a request for comments on the ECUT work and its objectives as described in the first stage of the meeting; and zhen went on to uncover, in as much detail as possible, the views of the engineers and managers involved. Briefing charts used for the meeting are available from the author.

The authors tried to focus on limitations in the state of the art of tribology that engineers in the organization face in doing their jobs. An effort was also made to determine what $R \& D$ activities were being funded by the company; with particular emphasis on distinguishing between generic research in tribology and other work. Section IV summarizes the findings for each of the 27 meetings.

Based on the non-proprietary information obtained, and information available from public sources such as corporate annual reports, the authors attempted to assess the total level of efforc on generic tribology research funded by industry in each of the categories shown in Figure III-1. The resulcs of this work is presented in Section $\mathrm{V}$, and summarized in Table $\mathrm{V}-1$.

Finally, an effort was made to synthesize concepts for research programs responsive to the users' needs (as defined in Sections III and VI A) inferred during the course of this assessment. Both management and technical issues were considered. The results are presented 1 n Sections VI and VII. 
F I GURE II I -1

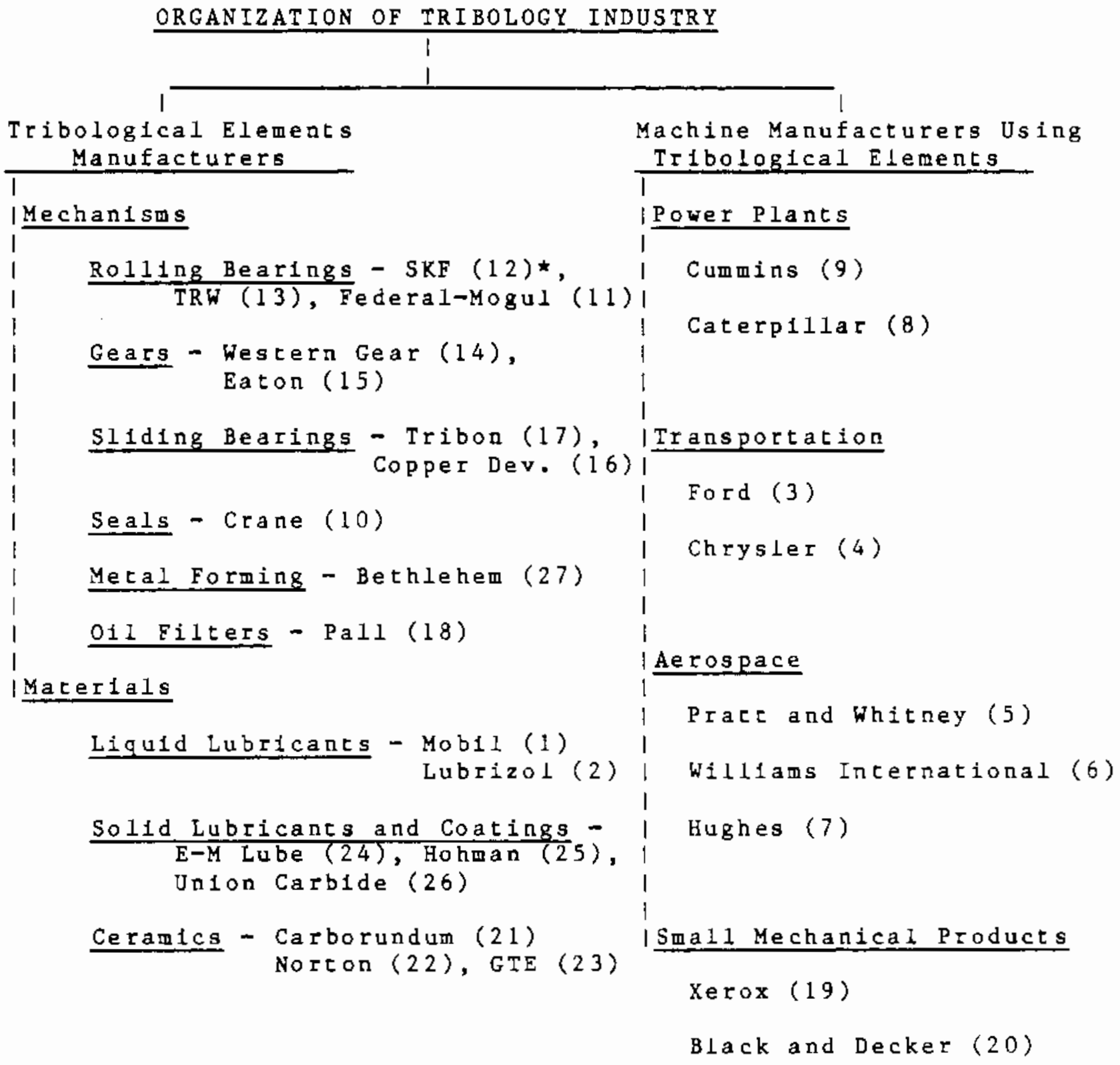

* Numbers in parentheses are the order of presentation in Section IV and in Table $V-1$. 
IV. INDUSTRY CONTACTS $\rightarrow 1$

A. Name/Address/Point of Contact:

MOBIL RESEARCH AND DEVELOPMENT CORPORATION

Dr. Patrick E. Fowles / Dr. Bernard M. Glliespie

Yanager Resources and Products Research Section

P. 0 . Box 1025

Princeton, NJ 08540

B. Category/Role:

LIQUID LUBRICANTS: One of the major manufacturers and suppliers of liquid lubricants for Industry and consumers. Leader in premium products featuring long life and fuel conservation (e.g. Mobil 1).

C. SaLes/R\&D Budget (1982):

$\$ 59946 \mathrm{M} / \$ 188 \mathrm{M}$

(Industry Average $\rightarrow$ Sales: $\$ 21501 \mathrm{M} \rightarrow$ R\&D Budget: $\$ 118 \mathrm{M}$ )

D. Level of Generic Tribology R\&D:

$\$ 1 \mathrm{M} /$ year (Estimated - Approximately 8 staff members full time.)

E. Generic Tribology R\&D Interests:

1. Understand role of lubricants in fuel economy: Direct method of measuring friction. Quantifying benefits of synthetics, friction modifiers, viscosity index improvers, service life. Understanding characteristics of synthetics, e.g. to lower nominal viscosity without increasing wear. Studying engine and power traln concepts including traction drive and hybrids. Some emphasis on role of piston rings using strain gages and independently supported cylinder Liners. Also conslderation of cam-followers. All work on fired engtnes. Contact with related work at University of Michigan. (Some results may be proprietary.)

2. Understanding rolling contact fatigue: Long time Mobil commitment. Studying effect of additives; mechanisms of interaction of rolling elements' surfaces and additives; effect of presence of water in system (suspect significant role of hydrogen embrittlement). Aiming ar "super lube" for fatigue. Working on wide variecy of testing techniques.

3. Elastohydrodynamics: Extending correlation formulas of ASME Wear Control Handbook. Trying to correlate molecular structure of Lubricant with performance, including effect of base stock Interaction with additives. Prefer semiempirical models, which may include measured traction 
coefficients, because detailed mathematical models tend to be too complex. Scudying phenomenology, theology, e.g. effect of gradient in constituents across layer and effect on performance considering relation of traction properties and fatigue.

F. R\&D Requirements/Recommendations:

1. RELATE FUNCTIONAL NEED OF LUBRICANT TO SPECIFICATION. This is a government role because oll industry may seem to have conflict of incerest in setting its own standards and specifications. Suggests possibillty of not-for-profit group as alternative. Underscanding of fundamental mechanisms is basis for specifications and therefore this type of generic research requires government support.

2. MAKING RESULTS OF RESEARCH BROADLY AVAILABLE TO INDUSTRY. Industrywide educacton may also be goverment role. Users (both industrial and consumer) benefit because they can choose lubricants wisely, and producers of better Iubricants also benefit with overall galn $1 \pi$ productivicy. Mid and smaller businesses without large resources benefit most. Possibiy start with producers of industrial gears. Stressed importance of increas 1 ng technical sophistication of American industry with existing research results. Increased sophiscication of customers believed to be advantageous to Mobil. Example in fatigue induced failures that are not recognized as such by industry.

3. CHARACTERIZING EFFECTS OF BASE STOCKS ON LUBRICANT PERFORMANCE. StIONg 1 Y support work in this area sponsored by ECUT at NBS.

4. FUNDAMENTAL, GENERIC INDUSTRIAL RESEARCH tends to be diminishing and increases need for government support.

G. Interest in Parcictpating in ECUT Planning:

Very willing to participate. Immediately prepared to identify staff member as point of contact. 
IV. INDUSTRY CONTACTS $\div 2$

\section{A. Name/Address/Point of Contact:}

LUBRIZOL CORPORATION

Dr. Frank Zalar

Director, Product Development

29400 Lakeland Boulevard

Wickliffe, OH 44092

\section{B. Category/Role:}

LIQUID LUBRICANTS: The leading company speclallzing in lubricant additives with about half its $r$ evenues and assets in this country. Competitors are Ethyl and divisions of some of the major oll companies. It considers itself a high technology company relying on expertise 1n developing specialty chemicals for its success. O1l companles manufacturing lubricants for the transportation industry are primary customers, and successful marketing depends on acceptance by equipment manufacturers. As a result, Lubrizol has a strong concern with the process of developing standards.

C. Sales/R\&D Budget (1982):

$\$ 802 \mathrm{M} / \$ 35.9 \mathrm{M}$

D. Level of Generic Tribology R\&D:

Lubrizol's R\&D budget is for product development. It does not have an identifiable generic R\&D program in tribology.

E. Generic Tribology R\&D Interests:

1. Testing techniques, speciflcations, and standards development are primary interests. Correlation of standard tests with fleld performance is a concern; along with the validity of the tests themselves, for example, the stability and unfformity of the engines. Statistics and repeatibility of the tests is a problem. Standards are strongly influenced by "Milspecs", with some tncldence of rigid specifications that are not related to field performance, and occasional additional specifications by OEMs.

2. The fivercar fuel economy tests cost about $\$ 35 \mathrm{~K}$ each and there was concern with reducing cost of the tests, and the requirements for retesting if the total costs go beyond the current rate of about $\$ 1 \mathrm{M}$ in 2 years.

3. Test engine development was of interest. Desirable for everyone to use the same standard engine. 
F. R\&D Requil rements/Recommendations:

1. Develop technology required in setring standards. This might 1nclude development of testing procedures and equipont. One contribution might be to supply 5 or 6 very well characterized base stocks 1 n large enough quantity to be used as standards in industrial testing. Effects of additives could be well characterized if the base stocks responded to different tests in different ways. Inventing new tests and deflaling standards would be beneficlal. Improvements to the flve-car tests and development of a standard eng1ne test are desirable.

2. There was substantlal comment regarding the studies of base stock characteristics at NBS. It was noted that the good correlation of the 4 -ball with the $5+$ car tests was interesting and valuable, but some reservations were Indicated about its applicabllity over wider ranges of lubricant types. There was agreement with the need for developing model compounds, but there was a problem in gett1ng pure, completely characterized, components when these are, themselves, complex compounds.

3. Theoretical and experimental techniques to carry out analysis of surfaces, in particular to understand better what makes additives stick.

4. Emphasis on analytical techniques for determining constituents, and for understanding mechanison was recommended.

5. Work on jmproving understanding of oll consumption mechantsms along the Iines proceeding at NBS was suggested.

G. Interest in Participating in ECUT Planning:

1. Lubrizol has sent representatives to reviews and will continue to do so. They also are willing to comment on DOE work pertinent to thefr interests.

2. There 1s some concern that the effect of some NBS activities, if they go beyond analysis and generic research wlll reduce the knowledge advantage Lubrizol now has over 1 ts competitors. This extends to asking questions that w11 reveal proprietary information. There is no problem with the NBS program as 1 t appears to be going at this time.

3. It was noted that 1ndustry would be sensitive when characteristics of commercial products were revealed in testing and other programs. 
IV. INDUSTRY CONTACTS $\div 3$

A. Name/Address/Point of Contact:

FORD MOTOR COMPANY

Mr. R. E. Baker

Manager, Fuels and Lubricants Department

Englneering and Research Staff

20000 Rotunda Drive

P.0. Box 2053

Dearborn, Michigan 48121

B. Category/Role:

TRANSPORTATION: One of the major automotive manufacturers in the United States and Internationally (market share in 1982 about $17 \%$ in the U.S., 12.9\% In Europe). Ford has incurred research and development costs over $\$ 1.5 \mathrm{~B}$ in each year since 1978, and stresses "functional" design features and high technology in public statements.

C. Sales/R\&D Budget (1982):

$$
\$ 37067 \mathrm{M} / \$ 1764 \mathrm{M}
$$

(Industry Average-Sales: $22862 \mathrm{M} \rightarrow$ R\&D Budget: $\$ 905 \mathrm{M}$. The R\&D expense includes the cost of developing new products.)

D. Level of Generic Tribology RED:

$\$ 1 \mathrm{M} /$ year (Estimate by authors based on the Fuels and Lubricants Department size of approximately 30 professionals with about $1 / 3 \mathrm{rd}$ of the effort related to tribology)

E. Generic Tribology R\&D Interests:

1. Strong 1nterest in fuel economy. Reduction of parasitic friction is a primary interest. Piston rings and valve gears are motivation along with interest 1n diesels. Problems arise on tradeoffs between reduction of parasitic friction and durability; for example, by possibility that lubricant viscosity reduction will lead to 1ncreased rate of wear. Friction/wear tradeoff a matter of concern across the board. This leads to an interest in mechanisms of boundary lubrication (See E. 2). Dry bearings are also of interest. Rolling elements introduce added expense, and ceramics are considered to be an option (See E. 3.) Another aspect is the effects of wefght reduction resulting in deformations with consequent misalignments leading to parasitic loads unaccounted for by the designer. 
2. Interest in boundary lubrication mechanisms were tied to understanding of propertles of lubricating olls. There is concern with interaction of combustion products with lubricating propertfes and desire to increase malntenance intervals. Work concentrates on physical properties, but increase in work on mechanisms is contemplated. F1ts and finishes of parts are an 1ssue. There 1s work on interpretation of 4+bal1 and plnton-d1sk test, espectally for correlating wear.

3. Ceramic machine elements were of great interest. One of the motivations is reduction of parasitic friction without incurring expense of rolling elements. Concern about surface properties for ofl retention and other tribological properties separate from material development.

F. R\&D Requirements/Recommendations:

There were no specific recommendations. The authors understood that the Ford engineers would welcame research results in their areas of interest.

G. Incerest in partic1pating in ECUT planning:

Substantial interest and enthuslasm for participating as an aid to the government prograt. Beneftctal for industry to share goverment sponsored research. Some concern about other particlpants. Would be reluctant to talk about own research. Have history of contributing and providing program evaluations to Congress. 
IV. INDUSTRY CONTACTS $\rightarrow 4$

A. Name/Address/Point of Concact:

CHRYSLER CORPORATION

Mr. John M. Corwin

Advanced Materials

Advanced Powerplant Engineering

P.0. Box 1118

Detroit, MI 48288

\section{B. Category/Role:}

TRANSPORTATION: Third largest of the "big three" automotive manufacturers. Market share in the U.S. based on unit sales in 1982 is about $9.5 \%$. Just emerging from a period of threatened bankruptcy, Chrysler has cut expenditures on organized research and does not have a dedicated research laboratory. In official public statements the emphasis on the quality, represented by the warranty period, is greater than the emphasis on new technology.

C. Sa les/R\&D Eudget (1982):

$\$ 10045 \mathrm{M} / \$ 307 \mathrm{M}$

(Industry Average--Sales: $\$ 22862 \mathrm{M} \rightarrow$ R\&D Budget: $\$ 905 \mathrm{M}$. The R\&D expense includes the cost of developing new products.)

D. Level of Generic Tribology R\&D:

Chrysler does not have an identifiable generic research activity in tribology.

E. Generic Tribology R\&D lncerests:

1. Strong desire for fuel economy motivates most of the tribological

interests. This is reflected in the following.

2. Betrer lubricating oils needed for gasoline engines, as well as diesels. Noted that soot absorbs zinc thiophosphate additive and that there is need for a chemical system not absorbed by carbon; and not poisonous, as phosphorus 1s, to catalytic exhaust converters.

3. Lighter weight parts sought to reduce inertia loads. Ceramics viewed as way to combine lighter weight and low sliding friction with durability, particularly resistance to fatigue and brinneling. Reduction of parasitic friction is a primary interest with the valve train belng emphasized. 
4. Improved dynamoneter testing sought as an a1d in developing better fuel economy.

F. R\&D Requi rements/Recommendations:

There was an emphasis on high Hertzian load ceramics operating in standard and degraded olls particularly with diesels, but including gasoline and novel

fuels.

G. Interest in participating in ECUT planning:

Substantial interest and enthusiasm for opportunity to use results of the government program. No explicit commitment to participace in planning, but apparent willingness to cooperace. 
[V. INDUSTRY CONTACTS -5

A. Name/Address/Point of Contact:

?RATT AND WHITNEY AIRCRAFT GROUP

Commercial Products Division

Yr. Richard P. Shevchenko, Head Bearing Coordinating Team

Engineering Department

400 Main Street

Rast Hartford, CT 06108

3. Category/RoLe:

AEROSPACE: Pratt and Whitney is one of the leading manufacturers of commercial and military jet aircraft engines with approximately $50 \%$ of the commercial market. In 1982 P\&W sold about $\$ 1.6 \mathrm{~B}$ worth of commercial engines and about $\$ 3.5 \mathrm{~B}$ in military engines.

C. Sales, R\&D Budget (1982):

Sales for United Technologies, the parent corporation for $P \& W$, is $\$ 13.6 \mathrm{~B}$ with about $\$ 4.5 \mathrm{~B}$ to the government. $R \& D$ budget was $\$ 0.83 \mathrm{~B}$ of corporate expense. Distribution of the corporate R\&D budget was not reported. It covers developmental costs at Mostek, which is in the highly competitive semiconductor business, the corporate laboratory, and the commercial developments at Stkorsky, P\&W, and the other divisions. It is to be expected that P\&W commercial technology benefits from the R\&D - including generic research - sponsored by DOD for the military engines. For example, military and commerclal englnes in the past have used the same bearings, but the ratings and lifetimes differ. The rwo groups are separate with product lines that differ widely in size and operational requirements. Mllicary and commerclal engine designs have recently diverged, and are being developed separately, so that commercially oriented generic R\&D needs are greater than ever. At approximately $6 \%$ of saies, the overall leve $\perp$ of $R \& D$ is comparable to other companies and induscries.

\section{Level of Genertc Tribology R\&D:}

There was no identifiable generic research in the comercial products deparcment. The solution of development problems when they arise, however, often involves high-powered research efforts.

E. Generic Tribology R\&D Interests:

1. Specific Fuel Consumption is a key interest, along with other factors important in commercial competition, weight and volume. This leads to higher temperatures and speeds with heavier loadings. Pressure to keep costs down is 
constant.

2. $M+50$ steel ball quality is a problem with over $50 \%$ of the failures being the balls. Investigation required to determine cause. Ceramic balls (princlpally silicon nitride) are under consideration.

3. Grinding burn failures are too frequent. Improvements required in process and inspection techniques.

4. Interest in cage design and vibration environment. Confidence is limited in existing dynamic analyses which are too costiy and cumbersome; therefore, st1l1 have to depend on shake tests in cage development.

5. Occastonal 1nnertring fracture problems suggest that improvements in fracture toughness of bearing materials would be beneficial.

F. R\&D Requi rements/Recommendations:

1. Would be in a position to apply research results pertaining to interests expressed in $\mathrm{E}$.

2. Supportive of work on boundary lubrication at NBS. Finds ASME Wear Control Handbook a useful tool.

G. Interest in Particlpating in ECUT PIanning:

There was ready willingness to particlpate in reviewing relevant ECUT programs. 
IV. INDUSTRY CONTACTS -- 6

A. Name/Address/Poinc of Concact:

WILLIAMS INTERNATIONAL

ir. Joseph Paletta

Mechanical Components Department

2280 West Maple Road

Walled Lake, MI 48088

3. Category/Role:

AEROSPACE: Williams is well known as the company that manufactures the engine sor the cruise missile. This is a highly engineered englne designed for a short lifetime, but with stringent requirements to meet military specifications for high rellability after long storage. The company also produces engines for remotely piloted vehicles and target drones. It is doing and has done development work on various new products ranging from a high-bypass turbofan for general aviation to a gas turbine for a tank. The engine sizes range from 15 to $1500 \mathrm{hp}$. Williams is privacely held and does not publ:sh information on gross sales and marker share.

C. SalesiR\&D Budget (1982):

Since wi-liams is privacely held, the information is not available publicly. The company is highly oriented to engineering work with about 500 engineers among the approximately 2000 employees.

D. Level of Generic Tribology R\&D:

There is no identifiable generic research effort in tribology.

E. Gener:c Trtbology RaD Interests:

1. Self-contained and maintenance-free lubricating systems of all types were of interest. Gas lubrication is preferred but unachievable under the high zhrust loads, and solid lubricant techniques with sufficiently long life are usually unavailable so that liquid and/or grease lubrication methods are required. A better understanding of the mechanisms and geometries to feed grease are sought in design work.

2. Volume constraints for peripheral equipment for the curbine, e.g. gear trains and pumps, dominate the design problem and produce strong incentive to operate at higher speeds and loads. To meet these problems mechanical designers are looking ac solid lubrication for bearings, gear drives and craction drives to achieve low maintenance with high perfomance, wear resistant materials including plastics, and gas lubrication (gas cemperatures ( $740 \mathrm{~F}$ ). 
3. Interest in seals similar to piston rings, particularly with materials with better properties than cast iron.

F. R\&D Requirements/Recommendations:

Primary concern was wh making existing generic results applicable to design problems encountered in everyday practice. Cited DARPA study at Hughes for producing important fundamental resules pertaining to solid lubrication of rolling element bearings, but felt that this study did not advance sufficiently to provide design information for general solid lubricated bearing application.

G. Interest in Participating in ECUT Planning:

General interest in particlpating in relevant meetings. 
IV. INDUSTRY CONTACTS -- 7

A. Name/Address/Point of Contact:

HUGHES AIRCRAFT COMPANY

Mr. Larry C. Lipp (MS F150) / Mr. Crawford R. Meeks (14S D149)

Technical Supervisor / Senior Scientist, Bearings and Lubricants

Technology Development Laboratory, Bullding Em-1

P.0. Box 902

El Segundo, CA 90245

B. Category/Role:

AEROSPACE: Hughes is a major millcary contractor, and has about $50 \%$ of the civilian market for communications satellites. As a contractor to DARPA (DOD) Hughes has managed a team of 18 companies doing a major research program funded by DOD to develop solid lubricated bearings suitable for the cruise missile engine.

C. SaLes/R\&D Budget (1982):

Total Sales $\$ 4.4 \mathrm{~B}$, approximately $\$ 900 \mathrm{M}$ non-military. Independent R\&D approximately $\$ 145 \mathrm{M}$.

D. Level of Generic Tribology R\&D:

It was not possible to determine reliably to what extent the generic research at Hughes was funded by the company, and to what extent by DOD. For example, Hughes had a related computer prograw involving the dynamics of bali bearlngs at high speeds which was believed to be proprletary, at least in part. The primary focus of the company funded research can probably be ascribed entirely to the clvilian area of communications satellites, which involves, primarily, problems of Lubrication in a vacum. A substantial part of the work funded by DARPA was of a fundamental nature involving analysis of crysca $\perp$ scruccures of solid lubricants with the aim of understandlng why some are tribologically desirable, and some not. Results of DARPA work have civilian application because high temperature materials can usually be applied at low temperature and because of the fundamental nature of the research.

E. Generic Tribology R\&D Interests:

1. Long lifetime without maintenance is objective for spacecraft. Launch loads with $90-120 \mathrm{ksi}$ Hertz stress sometimes control design. Hughes is concerned with fundamentals of wear failures and seeking ways to predict wear failures using regression analyses of wear test data and other rechniques. Low load conditions are of Interest because the lifetimes of the solid lubricants required in space are too short otherwise. Sacrificlal elements, e.g. 
separators, are used as source of lubricant in some applicacions. Magnetic levitation techniques is another approach being considered.

2. Machine components of interest include brushes for high current systems and seals for cryopums. There is mintmal tribological data avallable at cryogenic temperatures, e.g. for a seal in a reciprocating compressor. Improved materials and designs for precision ball bearings, such as hard coatings, ceramics and separator dynamics, are of incerest for longer life and improved precision requirements in space mechanisms.

\section{F. R\&D Requirements/Recommendations:}

There were no explicit recommendations and descriptions of research required other than what can be inferred from the interests described above. It was noted that the ASME Wear Concrol Handbook was not useful.

G. Interest in Participating in ECUT Planning:

Hughes can be expected to particlpate with ECUT in planning generic technology programs. 
IV. INDUSTRY CONTACTS $\rightarrow 8$

A. Name/Address/Polnt of Contact:

CATERPILLAR TRACTOR CO.

Mr. Melvin L. Greenhalgh

Manager, Analysis Division, Research Department

Technical Center

Peorla, Illinois 61629

B. Category/Role:

POWERPLANTS: Caterp1Ilar accounted for more than $25 \%$ of sales of mach1nery in construction and farming 1n 1982. About 26\% of Caterplllar's sales ( $\$ 1.7 \mathrm{~B}$ ) was of diesel and natural gas engines as powerplants for electric power generation, 1ndustrial, marine, and other applications or to other OEMs for highway trucks and other uses. The company asserts a "... strong emphasis on product-oriented research and engineering relating to the development of new or 1mproved machines, engines and major components thereof, and to the development of new and Improved machine tools and processes for use in manufacturing."

C. Sales/R\&D Budget (1982):

$\$ 6.469 \mathrm{~B} / \$ 234 \mathrm{M}$

(Industry AveragerrSales: $\$ 1328 \mathrm{M}+\mathrm{R} \& \mathrm{D}$ Budget: $\$ 43 \mathrm{M}$. The R\&D expenditure was for new prime product and major component development. An additional $\$ 29$ $M$ was expended by Caterpillar for engineering costs during the early production phase as well as ongoing efforts to improve present products.

D. Level of Generic Tribology R\&D:

There is no identiflable generic research activity in tribology, but there appears to be a significant effort related to interests indicated belos. The authors estimate the level of generic research in tribology to be, in aggregate, at a $2 \div 3$ person level, roughly $\$ 300,000$ per year.

E. Genertc Tribology R\&D Interests:

1. There is a strong interest in surface topography measurement and characterization. Concern is related to making specifications for new manufacturing processes with potentlal for lower costs. These require definition of parameters describing shape of surface as well as amplitudes currently spectfled. Identification of key characteristlcs required as well as techniques for measurement in production. Is sue is related to elastohydrodynamic phenomena and definition of "lambda" for boundary lubrication. Characterization of pits and spalls is also needed. Industry 
requires better quality control instrumentation and understanding of the relation of colerances to function, e.g. relating bearing noise indications of trouble to specification on waviness. Objective is not to aninimize surface roughness, but to find an optimum related to production costs, and ability to hold of1. This issue artses both in crankshaft journals and thrust bearings. Grinding, and 1ts inconsistencies, is one focus of the concern with surface topography. Elasticity of heav1ly loaded components is a related issue.

2. Increased understanding of ofl filter operation is sought. Want to detemine whether best strategy might be simply to extend filter effectiveness to smaller particles and certain molecular species. Concelvably it would be possible to add additives to sump and let filters take out debris and acids generated by combustion. Wear is seen related to cleanness of lubricaring oil.

3. Ceramics 15 of growng interest.

4. Caterp1llar is Involved in NBS work on base stock o1l characteristics.

5. Cavication in heavy duty bearings was identifled as a possible problem.

F. R\&D Requirements/Recommendations:

1. Suggested a government role to assist in understanding functional effect of surface copography, and in developing standards. Instrumentation is a key Issue since it is difficult to justify procuring instrumentation before there is a spec. Caterpillar is willing to contribute and participate, and is already dolng so as part of the ANSI B +46 group.

2. Another government role was seen in the development of test procedures and instrumentation for qualifying ofl filters.

G. Interest in Participating in ECUT Planning:

Would welcome an Invitation to particlpate in ECUT planning. 
IV. INDUSTRY CONTACTS -9

A. Name/Address/Point of Contact:

DIMMINS ENGINE COMPANY, INC.

:1r. Char..es L. White

Executive Director, Advanced Engine Technology

Dummins Jechnical Center, Mail Stop 50165

1900 McXinley Avenue

Solumbus, IN 47202

B. Category/Role:

POWERPLANTS: Cummins is the world's largest independent manufacturer of diesel engines with a $41.6 \%$ share of the U.S. large diesel powered truck market, including over $60 \%$ share of heavy-duty Class 8 truck engines. Cummins has the reputation of producing the premium quality truck engine; for example, its engines are offered in competition with Gl engines on thi trucks.

$\therefore$ Sales,'R\&D Budget (1982):

$\$ 1.59 \mathrm{~B} / \mathrm{S} 54 \mathrm{M}$

The Cummins figure of $3.4 \%$ of sales is slightly higher than the $3.1 \%$ for Caterpil.lar, which has engine sales of comparable magnitude. Automotive car and truck R\&D averages $4 \%$ of sales. Automotive parts and equipment R\&D averages $2.3 \%$ of sales.)

J. Level of Generic Tribology R\&D:

There has been to date no identifiable effort in generic tribology. Tribology work is directed to specific products (including the DOD sponsored work on the adlabatic diesel) and problem solving. Because of the emphasis on higher temperatures there is intense effort on tribology with an estimated 20 to 25 engineers and scientists working on projects involving tritology at least part of the time. Under these circumstances, there is undoubtedly significant effort on what can be cermed generic RSD in tribology, but because it is so intimately tied to product developmenc there is little impact on the state of the art for industry as a whole.

\section{E. Generic Tribology R\&D Interests:}

1. Primary interest is in approach to adiabatic diesel and tribological problems arising from higher in-cylinder temperatures. Ceramics are an elemenc in the solution to the problems. Have begun development of model which is proprietary (at leasc at this time because of pending proposal). 
2. Problem with sliding-contact bench tests such as the Falex, and also expected with the NBS four-ball tests, is that viscous effects and boundary

lubrication effects cannot be separated easily.

F. R\&D Requirements/Recommendations:

1. See big gain in cooperative $R \& D$ to enable designer to predicc $t r i b o l o g i c a\rfloor$ performance of design and materials. At least 6 people are needed for

"critical mass", with a long term commitment (e.g. 5 years), but funding can be on an incremental basis.

G. Interest in Parcicipating in ECUT Planning:

Will welcome opportunity to participate in ECJT planning. 
IV. INDUSTRY CONTACTS -10

A. Name/Address/Po1nt of Contact:

CRANE PACKING COMPANY

Mr. Jon Hamaker

Ass1stant D1rector, Research \& Development

6400 Oakton Street

Morton Grove, Illinois 60053

B. Category/Role:

MECHANISMS/SEALS: John Crane, a subsidiary of Houdallle, Inc., is a leader in eng1neered fluid seallng systems. It manufactures a varlety of shaft seals, plston rings, packings and gaskets of metal, fabric, carbon, TFE and other plastics. Face sesls are primary product. Packlng gland seals secondary.

C. Sales/R\&D Budget (1982):

houdallle, the parent company of John Crane, is privately held. Sales and data on R\&D expense is not publicly avallable. It is generally believed that Crane has somewhat wore than $50 \%$ of the market.

D. Level of Gener1c Tr1bology R\&D:

$R \& D$ at Crane is almost entirely product development, but the approach is very sophisticated with substantial use of academic consultants. The authors estimate about a $\$ 300,000 /$ year level of generic tribology R\&D.

E. Generic Tr1bology R\&D Interests:

1. Characterizgtion of surfaces under a broad range of conditions and the technologies for dolng so are major Interests. With fluld f1lm thicknesses at critlcal seal contacts as low as 100 microinches, geometric factors such as wgviness and roughness, material anisotroples and deflectlons (hence local mechanical and thermal properties) are important considerations.

2. Research is primarily in face seals using hydrodynamic lift. Time variations during run-1n are under study, very high speeds, and instablifties, e.g. Burton's instability which results from moving hot spots.

3. Difficulties In making specifications for carbon are significant because of the statistcal variations and antsotroples in material parameters such as elastic modulus, and density.

4. There 1s a need for quality control instrumentation at the production level. 
5. Where rellability is paramount, as in the coolant pump of a nuclear plant, it is necessary to predict fallure modes and times to overhaul.

F. R\&D Requirements/Recommendations:

1. Suggested research 1 n surface films and wear mechantsms that will lead to methods of predicting wear $11 \mathrm{fe}$. Understanding of mechanisms are important, for example, to differentlate between effects of $P$ and $V$ in PV specifications.

2. Goverment support of development for technlques of metrology is desired.

3. Efforts to make available existing research results are suggested.

G. Interest in Participating in ECUT Planning:

Strong interest in participation. 
IV. INDUSTRY CONTACTS $\rightarrow$ II

A. Name/Address/Point of Concact:

FEDERAL-MOGUL CORPORATION

Mr. Paul Cowley

Supervisor, Contracts and Metrology

Ball and Roller Bearfing Group Research

3980 Research Park

Ann Arbor, MI 48104

B. Category/Role:

ROLLING BEARINGS: Federal-Mogul is one of several suppliers of rolling bearings and other equipment to the vehicle and machinery industries. The Ball and Roller Bearing Group accounts for about $31 \%$ of sales, the Engine and Transmission Products Group for about 28\%, and the Sealing Products Group for about $15 \%$ of sales in 1983. $73 \%$ of sales were within the U.S. There is a great emphasis on low cost and reliability in processes and production.

C. Sales/R\&D Budget (1922):

\section{$\$ 735 \mathrm{M} / \$ 12 \mathrm{M}$}

(The R\&D expenditure level of $1.6 \%$ of sales is an unofficial, approximate figure cyplcal of the automotive parts and equipment industry, which has total annual sales of $\$ 15.7 \mathrm{~B}$, and an average R\&D expenditure of $2.3 \%$ of sales.)

D. Level of Generic Tribology R\&D:

Federal Mogul has 3 research laboratorles in the Ann Arbor area with approximately 90 people doing tribologically related research. It is estimated that about $20 \%$ is not directly product related. The authors escimace about $\$ 1-2 \mathrm{M}$ work on generic tribology R\&D.

\section{E. Generic Tribology R\&D Interests:}

1. Characterization of surface finish is a leading interest especially for boundary lubrication with Low values of lambda.

2. Effects of surface finish for low speeds have not been well established. Existing experimental results seem to correlate with theory except at low speed. Low speed lubricants are soughe. It appears that viscosity increases are not helpful.

3. There is concern with estimates of lifetime including effects of contamination and heat treatmenc. 
4. System analygis of whole machine is reguired, including deflections and ocher causes for misalignment, to define operating regime in which product is designed to operate rellably so that constraints on customer are well defined. Educating customers to underscand Limitations of bearings is a concern. Interested in having ASME, ASLE, or AFBMA define specifications.

5. Ceramics a continuing and growing interest. As one of the original and major participants in the development of ceramic rolling bear1ngs, Federa-Mogul has manufactured and evaluated full-scale ceramic roller bearings as well as ceramic elements in rolling contact fatigue tests.

F. RED Requirements/Recommendation:

Interested in cooperative research or joint work with the government, primarily in the area of boundary Lubrication, but would consider other areas that mighe result in product improvement.

G. Interest in Participating in ECUT Planning:

General willingness to review ECUT results and make comments. 
IV. INDUSTRY CONTACTS - 12

A. Name/Address/Point of Contact:

SKF INDUSTRIES, INC.

Mr. Tibor E. Tallian / Dr. L. D. Wedevan

SKF Technology Services

1.100 First Avenue

KIng of Prussia, PA 19406

B. Category/Role:

FOLLING BEARINGS: SKF produces bearings for a broad market ranging from sophiscicaced aerospace bearings in small numbers to ordinary industrial bearlngs sold in large numbers. It has been progressive in its technology with substantial research efforts, at least partly government funded. SKF has also been a leader in efforts to educate its customers through technical seminars.

C. Sales/R\&D Budget (1982):

SKF is a privately held company based in Sweden with branches in western Europe. Information on sales and R\&D budget are not made public.

D. Level of Generic Tribology R\&D:

[nformation not avallable

E. Generic Tribology R\&D Incerests:

1. Ceramics and surface modification technologies are of 1nterest at this time. Applications of interest include rolling concact for extreme environments (including high temperature). Would like to be able to predict baslc wear properties of ceramics. Have to be concerned with Iubes also.

2. Scuffing phenomena has received detailed consideration (See L.D. Wedeven, "Concept of: JoInt Program on the Tribology of Load Capacity", NASA Lewis Research Center, May 1983). Problem is very difficult and strongly incerdisciplinary. Required because predictions of load capacity and lifetime, such as Ryder Gear test, are unreliable. This greatly slows development process.

F. R\&D Requirements/Recommendations:

1. Need more rellable tribological models in mixed film regime for life prediction in complex computer models.

2. The SKF program on solid lubrication sponsored by DOE would have greater 
technical potential if there were more fundamental tribology support from universities as well as more intimate interaction with engine builders.

G. Interest in Participating in ECUT Planning:

Apparent wfllingness to participate.

H. Other Comments:

1. ASME Wear Control Handbook used but only occasionally.

2. Interest in Cooperative R\&D program depends on defining subject matter suitable for SKF. Suggested SKF customers may be appropriate sponsors or co-sponsors. 
IV. INDUSTRY CONTACTS $\rightarrow 13$

A. Name/Address/Point of Contact:

TRW, INC.

Dr. Ronald Keller

Ma1l Stop 37, Powder Technology Section

Materials and Manufacturing Technology Center

23555 Euclid Avenue

Cleveland, OH 44117

(About 16 members of the TRW staff particlpated in the discussion including representatives of the Automotive Sector and Bearling Division of the Industrial Products Group.)

\section{B. Category/Role:}

TRIBOLOGICAL ELEMENTS: In this as sessment TRW was originally considered primarily a representative of the rolling bearing manufacturing industry, but its activitles are much broader in aggregate. It includes three sectors, Industrial and Energy, Car and Truck, and Electronics and Space Systems. (The latter is based in California and did not participate in the meeting which was held in the Cleveland area.)

C. Sales/R\&D Budget (1982):

$\$ 5132 \mathrm{M} / \$ 109.1 \mathrm{M}$

(Automotive Sales $-\$ 1536 \mathrm{M}$, Industrial and Energy Sales $\$ \$ 1392 \mathrm{M}$, Electronics and Space Systems Sales - $\$ 2205 \mathrm{M}$.)

The R\&D expenditure is the corporate budget and does not include government sponsored R\&D of $\$ 1175 \mathrm{M}$ (primarily in electronics and space) and $\$ 139 \mathrm{M}$ expended for new product development. Though TRW is classified as a conglomerate by Business Week, there is a great deal of Interchange within the corporation so that the high level technical expertise of the aerospace/defense sector is avallable throughout the company. Thus the nominal figure for R\&D as $2.1 \%$ of sales does not accurately reflect the level actually expended. As a reference, Timken spent $\$ 18.9 \mathrm{M}$ on R\&D which was $1.9 \%$ of sales, and Bend1x $\$ 89.6 \mathrm{M}$ which was $2.2 \%$ of sales, figures which Include expenditures for new product development.

D. Level of Generic Tribology R\&D:

There is no identifiable nontproprletary generlc tribology R\&D work funded by TRW in the segments visited. 
E. Genertc Trtbology R\&D Interests:

1. Quality control and nondestructive evaluation was a central interest. Th1s was expressed in such terms as predicting reliability, and wear 11fetime; and the relation between incidence and severity of defects to lifetime. Surface characterization was considered an 1mportant related aspect. Generally there was a desire to be able to use bench testing rather than expensive englne tests.

2. Interest in ceramics was evident. NDE and $Q C$ were considered key to success in ceramics technology.

3. Sealing technology, operation under lubrication starved conditions, and solid lubrication was of interest in valve design.

F. R\&D_Requirements/Recommendations:

1. DOE is not seen to be disseminating Information effectively to companies not closely involved with its sponsored research.

2. Collaboration of Industry, academia and government has proven very effective in the Sandia combustion program. Fostering collaboration and integration has to be a continuous effort.

G. Interest in Particlpating in ECUT Planning:

Very willing to partictpate in ECUT planning process.

H. Other Comments:

1. Have a potential interest in cooperative R\&D that is closely ilnked to directed basic or generic research. Fundamental areas of interest include material characterization and wear prediction.

2. Commented that tribology is as Important as combustion to industry.

3. Sponsoring a limited amount of academic research. 
IV. INDUSTRY CONTACTS +14

A. Name/Address/Podnt of Contact:

WESTERN GEAR CORPORATION

Dr. Lofti E1-Bayoumy

Applied Technology Department

14724 East Proctor Avenue

Post offlce Box 1040

City of Industry, CA 91744

B. Category/Role:

GEARS: Western Gear, a subsidlary of Bucyrus+Erie is one of several companies producing drives, holsts, actuators, and a varlety of mechanical systems. Applications are strongly for aerospace, and it has from $10-25 \%$ share of this market.

C. Sales/R\&D Budget (1982):

Figures are aggregated into BucyrustErle reports, but it $1 s$ possible to estimate roughly $\$ 120 \mathrm{M}$ sales out of a total of $\$ 687 \mathrm{M}$ for $B \div E$. $R \& D$ for $B \vdash E$ overall is $\$ 18.5 \mathrm{M}$ or $2.7 \%$ of sales.

D. Level of Generic Tribology R\&D:

There is no tdentiflable effort in generic tribology R\&D

E. Generic Tribology R\&D Interests:

There is an interest in improving the rellability of specifications of all types, for example, scuffing predictions and bearing vendors' safety factors which are belleved too conservative.

F. RSD Requirements/Recommendations:

There is a general need for predicting performance such as load and speed limits for scuffing and for bearing design. Generally the requirements tend to application of existing research results rather than the generation of new fundamental data.

G. Interest in Participating in ECUT Planning:

Very interested in participating in planning and review of ECUT program. 
H. Other Comments:

1. Did not use ASME Wear Control Handbook.

2. Have participated and continue to be interested in participation in cooperative programs. 
IV. INDUSTRY CONTACTS -- 15

1. Name/Address/Point of Contact:

כATON CORPORATION

Jr. Lamont Eltinge

Jirector of Research

26201 Northwestern Highway

P. 0 . Box 766

Southfleld, MI 48037

B. Category/Role:

GEARS: Though Business Week lists it in the Automotive Parts section, from 1979 to .982 , Eaton's business has changed from $79 \%$ vehicle components and $21 \%$ electron:c and electrical to $46 \%$ and $54 \%$ respectively. In its annual report it stresses integration of electrical and mechanical components in future development. Eaton is active in government funded projects and is increasing its DOD sales.

2. Sales, R\&D Budget (1982):

$\$ 2453 \mathrm{M} / \$ 100 \mathrm{M}$

(Vehicle component sales are given as $\$ 1129 \mathrm{M}$, but R\&D expenditures for vehicle components alone at Eaton are not available. Industry average $\$ 982$ $M / \$ 23 M . ;$

J. Level of Generic Trlbology R\&D:

No identifiable body of fundamental or generic R\&D in tribology. Corporate R\&D is strongly oriented to development and improvement of products and materials.

Z. Generic Iribology R\&D Interescs:

1. Application of NBS research on base stock components is of some interest. Th1s wouid include operation of the complete oil and interaction with surfaces of differenc kinds. Techniques for producing lubricant specifications that can be interpreted in terms of performance characteristic and function are required and not available. Understanding of physical and chemical phenomena and interrelations is seen as route to improved application of NBS results.

2. Concern that low viscosity lubricants for reduced friction may introduce wear problems.

3. Interested in potent1al for ceramics. Need to consider surface properties including, finish, porosity, inclusions, and solid lubricant coatings. 
Application to hydrostatic pump of interest because of dimensional stability thermally, along with potential for low friction and low wear.

4. Application of fracture mechanics techniques in non-contact cases to tribology, i.e. spalling from contacc facigue was discussed. Corrosion and scress-corrosion cracking to start of failure a possible factor. Related application of these results would be to make-and-break electrical contacts. Hardening of surfaces to reduce failures by techniques such as shot peening is considered.

5. Material properties, e.g. polywer/polymer behavior always under investigation in effort to use low-cost plastics.

6. Interest in techniques for measuring bending stresses at gear cooth roots.

7. Characterizacion of surfaces discussed in context of technology for generating various surfaces and defining finish required for various applicacions.

F. R\&D Requirements/Recommendations:

1. Application of available research resules seen as a high priortly. Eacon is always trying to use the best available techniques for design prediction.

G. Interest in Participating in ECUT Planning:

Would welcome invitation to participate.

H. Other Comments:

1. ASME Wear Control Handbook does not appear to be used extensively

2. Interested in cooperative R\&D that would fill Eaton's needs. 
IV. INDUSTRY CONTACTS - 16

A. Name/Address/Point of Contact:

COPPER DEVELOPMENT ASSOCIATION

IIr. Stuart Lyman

Senior Vice President

Greenwlch Office Park No. 2

F'. O. Box 1840

Greenwich, CT 06836-1840

F. Category/Role:

SLIDING BEARINGS: The Copper Development Assoclation represents 19 companies engaged in producing bronze bearings commonly used in electric motors and other mechantsms where cost is a primary consideration.

C. Sales/R\&D Budget (1982):

Sales information not readily available. Assuming chat $20 \%$ of the copper used in castings is for bearings at $\$ 1 / 1 \mathrm{~b}$, annual sales are about $\$ 100 \mathrm{M}$. The manufacturers represented by CDA do not do a significant amount of R\&D.

I1. Level of Generic Tribology R\&D:

None

E. Generic Tribology R\&D Interests:

Veveloping interactive computer design for hydrodynamic bearings. May extend this work to boundary lubrication regime. Program will be made avallable through the Association. NBS data may be used in these programs.

F. R\&D Requi rement $\mathrm{s} /$ Recommendacions:

No suggestions offered. It would appear that research results in a form applicable to sliding bearing design predictions would be useful.

G. Interest in Participating in ECUT Planning:

Would depend on relevance of subject. 
IV. INDUSTRY CONTACTS $\rightarrow 17$

A. Name/Address/Point of Contact:

TRIBON BEARINGS DIVISION

Mr. Donald Moyer

Englneering Manager

5581 West 164 th Street

Cleveland, $\mathrm{OH} \quad 44142$

B. Category/Role:

SLIDING BEARINGS: Tribon produces highly englneered bearings and assemblies in small quantities, primarily for the aerospace lndustry. Beginning with carbon'graph1te materials, the company now features polyimide components and products of self lubricating materlals including teflon, nylon, composites, and oll/bronze. Custom design and close interaction with the customer are key attributes of Tribon's operation. Tribon is a division of Pure Industries.

C. Sales/R\&D Budget (1982):

Based on total work force of approximately 70 people including about 10 engineers, for a company of this type, the authors estimate sales of $\$ 5 M$ and total engineering costs of $\$ 1 \mathrm{M}$, of which probably less than half is $R \& D$.

D. Leve1 of Generic Tr1bology R\&D:

R\&D at Tribon is almost wholly product related. There is no definable generic R\&D.

E. Gener1c Tribology R\&D Interests:

1. Accelerated $11 f e$ testing is of interest, particularly in qualifying materials and components for long lifetimes.

2. Have a continuing interest in materlal development and the state of the art in trlbology. Fam1liar with Hughes DARPA program.

F. R\&D Requilrements/Recommendations:

Stressed communication of technical results in a form useful to industry.

G. Interest in Participating in ECUT Planning:

May partlcipate in areas of direct interest. 
IV. INDUSTRY CONTACTS $\rightarrow 18$

A. Name/Address/Point of Contact:

PALL CORPORATION

Dr. William M. Needelman

Senior Staff Sclentist

30 Sea Cl1ff Avenue

Glen Cove, NY 11542

B. Category/Role:

FILTERS: Pall began as a manufacturer of sintered metal filters capable of supporting high pressure differences and now produces cleanable and disposable filters of all kinds for liquids and gases. It is a technical leader in its field wth a base that originated in the aerospace 1ndustry (29\% of Pall sales), and has expanded 1nto the fluld process ( $47 \%$ ), flutd power (13\%), and blomedica1 ( $11 \%$ ) Industries. Pall products are used to remove particles ranging in size from about 0.04 to over 100 micrometers. It appears that after being stimulated by the accouplishments of aerospace filtering technology, other industries are growing more sophisticated and innovative in their approach.

C. Sales/R\&D Budget (1982):

$\$ 196 \mathrm{M} / \$ 7.3 \mathrm{M}$

(R\&D expenditure at the rate of $3.8 \%$ of sales is about $50 \%$ greater than the average for the Machinery industry,)

D. Level of Genertc Tribology R\&D:

No idertiflable generic research in tribology. R\&D is orlented to materlal and prcduct development.

E. Generic Tribology R\&D Interests:

1. Concern with effects of debris and other contaminants, mostly water, but including other solvents, chlorine compounds, acids, and salts. Problems are similar for hydraulic power and Industrial lubrication systems except for the different ofls. Possibility that contaminants and debris are catalytic and that small particles more important than large (e.g. smaller particles do not settle, and there are more of them). Need to identify and predict source of contaminants (e.g. sliding wear in alrcraft hydraulics). Conjecture that skidding in rolling element bearings is contaminant related. It would make sense, for example, to have a contamination factor incorporated into bearing Iffe design. It is also possible to have lower limits of contamination that are insignificant. 
2. Improved measurement technology is needed to Improve measurement and counting of submicron particles and in field analysis for water.

3. Experiments on sliding wear that take into account contaminants are needed. This is becoming more important as longer lived o1ls are used. There is a conjecture that anti-wear additives act like Lubricants for the wear particle cutting action. Need to measure and understand "abrasivity" of wear particles (not powders) as a function of parameters such as hardness and shape.

F. R\&D Requirements/Recommendations:

1. Recommends government support development of functional standards related first to size then to species of contaminants (see E. 1) since this involves efforts that industrial firms cannot justify individually. Standards and specifications that make possible the relation of function, e.g - wear life, to cleanness of oils is lacking and would be useful.

2. Recommends government do standards and calibration work related to development of measurement technology (See E. 2). Development of devices and products for measurement should be industry's job.

3. Recommends government develop and/or support research leading to better physical understanding using theoretical and experimental analysis with output being mathematical models and physicochemical data for work described in $E$. 1 to 3 .

G. Interest in Partic1pating in ECUT Planning:

Welcome ECUT activitles and would welcome invitation for particlpation in planning •

H. Other Comments:

Have contributed to cooperative R\&D programs and remain interested in such programs. Contributions "in kind" might be more useful than funding in some cases. 
IV. INDUSTRY CONTACTS 19

A. Name/Address/Point of Contact:

XEROX CORPORATION

Dr. Juris P1rvics

Princtpal Scientist and Area Manager

Mechantcal Engineering Sciences Area

141 Webber Avenue

North Tarrytown, NY 10591

B. Category/Role:

SMALL MECHANICAL PRODUCTS: Xerox is in the "information processing: office equipment" category according to Business Week. It 1s second largest in the entire information processing industry, 1ncluding all categorles, after IBM. The rellability and durability of almost all of Xerox' products depend 1n sone way on mechantsms with tribologlcal interactions.

C. Sales/R\&D Budget (1982):

$\$ 8456 \mathrm{M} / \$ 565 \mathrm{M}$

(Xerox accounts for $56 \%$ of the sales in the cacegory of "information processing: office equipment". Omltting Xerox, average sales/R\&D figures for the 13 other companies in this field are $\$ 509 \mathrm{M} / \$ 16 \mathrm{M}$. Th1s includes, for example, Wang $+\$ 1159 \mathrm{M} / \$ 87 \mathrm{M}$, and Bell \& Howe $11-\$ 612 \mathrm{M} / \$ 21 \mathrm{M}$.)

D. LeveI of Gener1c Tribology R\&D:

There is a great deal of work on mechanical devices that is generic and not directly product related, but there is no 1dentifiable body of generic research in tribology at Xerox.

E. Genertc $\operatorname{Tr} 1$ bology R\&D Interests:

1. Techniques for prediction of wear and lifetime are needed. One example of the application will be to estimate performance of production camponents, which are made out of plastles or composites, from performance of prototypes which are machined out of metal and other materla1s. The ava1lable "knowledge base" for producing design calculation techniques is grossly inadequate and this impedes innovation.

2. Worklng on diagnostics software that wlll make it more practical to infer detalled Information about the nature of contacts in the parts of a mechanical device that are not accessible, from measurements at parts of the device that are. 
F. R\&D Requirements/Recommendations:

1. Belleves DOE should be doing work on fundamentals involving characterization of surfaces and their interaction. Work should not be limited to bearings. Did not think screening with pinrontdisk tests, alone, is basic, and that current need to rely on such tests suggests there is a lack of basic information avatlable for designers.

G. Interest in Particlpating in ECUT Planning:

Want to participate in guidance of ECUT program.

H. Other Comments:

1. Xerox is interested in "expert work station concept" to fac1litate application of research results in design. "Artificial intelilgence" approach is to enter into dialog and Infer level of knowledge and area of interest of data base user. This development is seen as a long term possibllity with great potentlal. Objective is to make data, such as that available tn the ASME Wear Control Handbook, which has limited utility now, accessible on a broader scale. 
IV. INDUSTRY CONTACTS $\div 20$

A. Name/Address/Point of Contact:

BLACK AND DECKER MANUFACTURING COMPANY

Mr. Gerald Rescigno

Engineerfing Manager, Advanced Technology

701 East Joppa Road

Towson, MD 21204

B. Category/Role:

SMALL MECHANICAL PRODUCTS: Black \& Decker manufactures small tools and appliances for consumers and industry. This is essentially its only business. B\&D obviously has a large fraction of this market, but the figure is unavałlable.

C. Sales/R\&D Budget (1982):

$\$ 1160 \mathrm{M} / \$ 30 \mathrm{M}$

D. Level of Generic Tribology R\&D:

R\&D is allocated to product development. There is no identiflable generic research in tribology at Black \& Decker.

E. Generic Tribology R\&D Interests:

1. Low friction bushings are of interest with coefficlent of friction lower than currently avallable level of 0.15 .

2. Low nolse gears operating at high rpm (eventually to exceed 32,000 ) are of interest under competitive pressure to increase performance and reduce stze and weight whlle keeping costs low.

3. Have done 11mfted work on possible use of alumina where high temperature and stiffness is required. Hot-pressed material too expensive.

4. Tribological fallures due to dirt, lubrication distress, and cage failures resulting from excessive vibration.

5. Generally interested in DOE work presented. Least 1nterested in high temperature applications.

6. Interested in powdered metals with relatively Iow $(0.7)$ theoretical density for reduced material costs.

7. Interest in solid lubrication techniques. 


\section{F. R\&D Requirements/Recommendations:}

1. Characterization of surfaces is needed to 1mprove techniques for making design specifications. Improvement is required to specify materlal and processing by more rational methods.

2. Interested in obtalning predictive methods for designer. Have computer programs for stress, deflection, and vibration analysis, for example, but none in tribology. Require methods for understanding mechan1sm of wear and predicting lifetime. Currently can design adequately. Problem is in going to more stressful condtions in response to competitive pressures.

\section{G. Interest in Particlpating in ECUT Planning:}

Participation would depend on spectfic technical area involved.

H. Other Comments:

1. Have heard of ASME Wear Control Handbook, but do not use 1 .

2. Would consider cooperative R\&D depending on program. 
IV. INDUSTRY CONTACTS -21

A. Name/Address/Po1nt of Contact:

SOHIO ENGINEERED MATERIALS COMPANY (FORMERLY THE CARBORUNDUM COMPANY)

Dr. Roger S. Storm

D1rector, N1agara Falls R\&D Center

P. O. Box 832

Niagara Falls, NY 14302

B. Cacegory/Role:

CERAMICS: Carborundum has been one of the world's major abrasives companies but now Sohio is investing in new technology for the long term in structural ceramics.

C. Sales/R\&D Budget (1982):

The former Advanced Materials Division of Carborundum U.S. has been 1ndependent of the abrasives business since August 1983 and is a wholly owned subsidiary of SOHIO, as is Kennecott Copper. The Division has about 120 engineers, of which about 22 are engaged in development of new materials including between 1 and 2 professlonals specializing in tribology. Based on this, the authors estimate a very substantlal equipment and operating budget for R\&L.

D. Leve:1 of Gener1c Tribology R\&D:

Company sponsored RSD, Including that related to tribology, is focused on material development. There is no 1dentiflable body of generic research in tribology, but the authors estimate that in aggregate there is a level of effort in generic research of about 2 people.

E. Gener1c Tr1bology RSD Interests:

1. Very interested in DOE sponsored pin*onrdisk testing with particular emphasis on SIC.

2. Concerned with relating laboratory testing of face seals to operational perfomance. Alphatsilicon carbide and alumina among materials investigated.

3. Surface characterization a problem. F1nd need for parameters to describe properties other than roughness.

4. Investigating solld lubricants incorporated in sintering and tempering process for SiC system.

5. Interested In application of ceramics to heat engines which leads to 
high-temperature tribological problems. Expect to benefit from working with TACOM and from feedback from customer tests of advanced materials. Funding Penn State and DHR In area of sliding friction with posstbility of DOE support in some areas. Also have supported work at the University of Massachusetts. Considering materials, surface characteristics, temperature, atmospheric species, sliding velocity, load and wear debris. Applications to bearings emphasized.

6. Hardness testing and crack inftiation mechanics under study.

F. R\&D Requirements/Recommendations:

1. Require standardized guidelines for standardized testing of materla1s.

2. Recommended using people and factlitles of National Laboratories to deal with problems of interest to broad crossrsection of industry. Have worked closely with NASA on basic friction studies of alpha silicon carbide.

G. Interest in Participating in ECUT Planning:

Apparent willingness to participate.

H. Other Comments:

1. Express appreciation for ASME Wear Control Handbook, but do not Indicate actual application.

2. Interested in possibility of cooperative R\&D on standardized friction testing methods. See this work as including development of basic understanding of mechanics in friction contacts, espectally when materials of different hardness are rubbing.

3. Very critical of methods used and results obtalned in pinton-disk tests sponsored by DOE, especially in SiC. 
IV. INDUSTRY CONTACTS - 22

A. Name/Address/Point of Contact:

NORTON COMPANY

Dr. Maurice L. Torti

Senior Scientist, Industrial Ceramics Division

One New Bond Street

Worcester, MA 01606

B. Category/Role:

CERAMICS: Norton, with its $\$ 621 \mathrm{M}$ business in abrasives supplies $25 \%$ share of the world market. It also does about $\$ 300 \mathrm{M}$ business in drill bits and nachinery for the petrolem and mining industries, and about $\$ 300 \mathrm{M}$ in engineering materlals, principally plastics such as Tygon and industrial ceramics such as silicon carbide and alumina. Norton's work on silicon nitride engineering ceramics for tribological applications was the primary focus of the viste. The technical literature and references available indicate that this seramic has been the subject of substantial research and development for at least 10 years at Norton, but silicon nitrlde is not mentioned in the 1982 annual report.

C. Sales 'R\&D Budget (1982):

$\$ 1264 \mathrm{M} / \$ 25.8 \mathrm{M}$

(R\&D leval of $2 \%$ of sales is average for miscellanous manufacturing companies)

D. Level of Genertc Tribology R\&D:

R\&D is strongly focused on development of materials or manufacturing methods with about 60 people doing long-range research, with 30 Involved in core technologies relating to powder and sizing techniques. There is no identifiable body of genertc research on trlbology.

E. Generic Tribology R\&D Interests:

1. Cost-effective non-destructive evaluation techniques for surfaces are needed. Fluorescent dye cechnique is too costly for routine use.

2. Mechanisons for forming and consolidation of ceramics are of interest.

F. R\&D Requirements/Recommendations:

1. Work on surface physics and NDE techniques pertaining to wear and longevity of ceramics. 
G. Interest in Participating in ECUT Planning:

Indicate that invitation to participate in ECUT planning would be welcome.

H. other Comments:

1. Interested in possibility of making "in-kind" and possibly other contributions to cooperative R\&D. Technical focus desired would be work in NDE, and related work on surface physics directed to wear properties. Seek integration with ongolng efforts if possible. 
IV. INDUSTRY CONTACTS - 23

A. Name/Address/Point of Contact:

GTE PRODUCTS CORPORATION

Chemical and Metallurglcal Division

Mr. Jeffrey Gonzalez

Section Head, Ceramics R\&D

Hawes Street

Towanda, PA 18848

B. Category/Role:

CERAMICS: GTE is very active in the application of silican nitride as an englneering ceramic.

C. Sales/R\&D Budget (1982):

$\$ 12066 \mathrm{Y} / \$ 267 \mathrm{M}$

The Chemical and Metallurgica I Division is a small part of a large company which is carried under the telecommunications category in Business Week. Figures for the division are not available to the public.

D. Level of Generic Tr1bology R\&D:

No identifiable generic research in tribology.

E. Generic Tribology R\&D Interests:

1. Close contact with DOE sponsored pin-on-d1sk tests of ceramics. Interested in carrying on studies of silicon nitride applications to bearings. Collaborating with Lawrence Berkeley Laboratory (LBL) in this area.

2. Consider non-destructive evaluation key problem in ceramics development. They see requirement for laboratory tests that will define properties of materials in terms useful to their customers, $i . e$. that will make 1 t posstble to characterize how they function. Abradable seals is a typlcal area of interest.

3. Have substantial data base from samples that have been distributed, but lack correlation method that is useful.

4. Need methods for correlating vartations in ceramic powders and processing parameters with characteristics of ceramic. Hot isostatic pressing is primary approach. 
F. R\&D Requirements/Recommendations:

All of the above areas.

G. Interest In Particlpating in ECUT Planning:

Apparent willingness to participate.

H. Other Comments:

1. ASME Wear Control Handbook ava1lable but not used extensively. 
IV. INDUSTRY CONTACTS -- 24

A. Name/Address/Point of Contact:

E/M LUBRICANTS, INC.

Dr. Robert Gresham

Technical Director

Post office Box 2200

West Lafayette, IN 47906

B. Category/RoLe:

COATINGS: Operating 12 custom processing and sales operations controlled by the laboratory operation in West Lafeyette, $E / M$ is a major company that is dominated by sma11, independent local operations. "Soft", i.e. non-refractory coatings used as lubricants, derived mostly from aerospace technology, are the primary business (although electrical, anti-corrostve, and decorative applications are also covered). $E / M$ is a wholly owned subsidiary of Great Lakes Chemical Corporation.

C. Sales/R\&D Budget (1982):

$\$ 170 \mathrm{M} / \$ 6 \mathrm{M}$

(Figures are for Great Lakes Chemical, the parent company of $E / M$ ) The laboratory operation of $\mathrm{E} / \mathrm{M}$ is carried on by two senior professionals supported by a team of technicians.

D. Level of Generic Tribology R\&D:

There is no identiflable generic tribology research effort.

E. Generic Trtbology R\&D Interests:

1. Interested in fundamentals of surface interactions.

2. Four-ball testing technology being used and development of improved testing technique would be useful. Have some concern with humldity effects.

F. R\&D Requirements/Recommendations:

Correspond to interests (See E. above)

G. Interest in Participating in ECUT Planning:

Very willing to participate in ECUT Planning.

H. Other Comments: 
1. Report that ASME Wear Control Handbook has been useful.

2. Would consider particlpating in cooperative program of fundamental research in surface physics depending on speciflc program. Ceramics and high temperatures are of interest.

3. See need for "translator" between Industry and academia. 
IV. INDUSTRY CONTACTS - 25

A. Name/Address/Point of Contact:

HOHMAN PLATING \& MFG., INC.

Mr. Bernard C. Stupp

President

814 H1llrose Avenue

Dayton, OH 45404

B. Category/Role:

COATINGS: Hohman Plating is a small business with a total of about 54 employees. It $1 \mathrm{~s}$ well known throughout the 1ndustry for the quality and sophistication of 1 ts product and its abilities to solve problems espectally with hard coatings. It has many high-technology companies among its customers. Hohman sells coating materials, applles them on a fob basis, and occasionally solves coating problems in the customers' plant.

C. Sales/R\&D Budget (1982):

\$5-6 M sales. About 7 laboratory people.

D. Level of Generic Tribology R\&D:

There is no generic tribology research.

E. Generic Tribology R\&D Interests:

1. Interested in coatings of all kinds and techniques of application. Surface preparation and morphology of changes is key in many cases. Uses SEM, ESCA and other diagnostics in course of serving customers.

2. Recent published work in co-sputtering nickel and molybdenum disulfide.

F. R\&D Requirements/Recommendations:

1. Broad interest in coatings and surfaces as indicated in E.

G. Interest in Part1c1pating in ECUT Planning:

Would consider particlpating depending on substance of program and level of effort required.

H. Other Comments:

1. Would consider particlpating in cooperative R\&D on fundamental work at the molecular level involving behavior of two surfaces in relative motion. 
Decision would depend on nature of the research, the researchers, and costs. 
IV. INDUSTRY CONTACTS - 26

A. Name/Address/Point of Contact:

COATINGS SERVICE DEPARTMENT, UNION CARBIDE CORPORATION

Jr. Robert C. Tucker, Jr.

Associate Director, Materfals Department

1500 Polco Street

P. O. Box 24184

Indianapolis, IN 46224

B. Category/Role:

COATINGS: Union Carbide's Coatings Service Department specializes in coatings by detonation gun deposition, plasma spraying and ocher methods, some of which are proprietary. This department provides services at a nuber of facilities in the J. S. and overseas.

- Sales:R\&D Budget (1982):

Materials and equipment development work is done by the Technology Department located in Indianapolis.

There is no public information that relates sales and R\&D budget for the relatively small part of the corporation comprising this departmenc. For the corporation as a whole, the published R\&D budget of $\$ 240 \mathrm{M}$ or $2.6 \%$ of sales is probably irrelevant to tribology R\&D expenditures. Union Carbide Corporat1on is basically a primary chemicals producer and the involvement in tribology is Limited :o the Coatings Service Department, which is relatively small compared to the thole corporation, and to providing precursors to lubricants, also a relatively small proportion of the total chemicals and plastics sold by the corporation.

C. Leve1 of Generic Tribology R\&D:

Much of the development work is very basic with sophisticated diagnostics, including support from the corporate laboratory in Tarrytown, but all the R\&D carried on is directly related co product development. Thus chere is no definable body of generic research in tribology that is assembled and pubIished.

\section{E. Generic Tribology R\&D Interests:}

1. Wear cesting is a primary interest. Basic approach is to compare wear scars and other measurements on new materlals with parameters for well-known. ones. Problems ar1se in variacions of environment and lubricants (1.e. resulting from oxides or other atmospheric species), or lack of them, which 
may be inadvertent in some cases where the enviroment is inadequately controlled or not well known. Sees problem in lack of coordination berween work on lubricants and work on materials. Have to develop special testing techniques in some cases. For example, they developed slurry test for abrasive wear resistance of oilmdrilling equipment, then compared new materfal with material already in use.

2. Get involved in basic physics of adherence phenomena when required in special cases.

3. Consider ceramic coating of metals a compecitor for solid engineering ceramics.

F. R\&D Requi rements/Recommendations:

1. Development of a data base to facilitate testing. Involves development of standard tests of "real world" materlals as a baseline, and would deal with lubricants. (See E. 1.)

2. Need better understanding of microscopic wear and fundamentals of tribology, including the applicabilfcy of tribology to real world design and manufacture.

G. Interest in Participating in ECUT Planning:

Apparent willingness to participate.

H. Other Comments:

1. Have ASME Wear Control Handbook avallable but do not find it very useful. 
IV. INDUSTRY CONTACTS - 27

A. Name/Address/Polnt of Contact:

3ETHLEHEM STEEL CORPORATION

Mr. Walter C. Unangst

Technica $\perp$ Consultant, Deformat1on Processes

Homer Research Laboratories

3ethlehem, PA 18016

3. Category/Role:

METAL FORMING: Rolling steel ingots is a major part of the steelmaking process common to all major steel producers. Bethlehem is third largest, posting $17.8 \%$ of sales by American companies. (ARMCO makes another 18.3\% and U.S. Steel $62 \%$.)

D. Sales/R\&D Budget (1982):

$\$ 5260 \mathrm{~N} / \$ 46 \mathrm{M}$

(This ratio of $\mathrm{R} \& \mathrm{D}$ to Sales, $0.9 \%$ is largest in the steel industry. For ARMCO the figure is $0.6 \%$ and for U. S. Steel it $150.5 \%$, which includes a $31 \%$ increase over 1981 while the other major producers reduced R\&D expenditures. A11 of these companies had losses in 1982; but in 1981, when Bethlehem showed a profit, its expenditure on $R \& D$ though $8.7 \%$ greater than in 1982 , was only about $0.7 \%$ of sales.)

D. Level of Generic Tribology R\&D:

There is no definable program of genertc research in tribology. It is estimated that about $10 \%$ of the R\&D program pertains to longmrange work on a broad range of subjects with $90 \%$ on near-term problem solving. The authors estimate that the level of effort for generic work in tribology averages about 2 personis.

E. Generic Tribology R\&D Interests:

1. Primary interest is $1 n$ cold forming. Some modeling is being done. Parameters involved include temperacure, production rate, lubricant, power requirements (torque and $\mathrm{rpm}$ ), and (primarily for hot roling) the roll wear rate.

2. Stick/slip chatter an occasional problem.

F. R\&D Requirements/Recommendations:

1. There is a need for modeling that includes 3 -dimensional flow of the metal 
with variations in friction coefficient wich1n the roll bite.

2. Rational basis for selecting lubricants is required and noc available. Some vendors, notably Mobil, claim savings for cheir products but there is no testing cechnique for validating claims.

G. Interest in Participating in ECUT Planning:

Expressed desire to participace if requested.

H. Other Comments:

I. Association of Iron and Steel Engineering has funded and carried out cooperative R\&D pertaining to steel making.

2. Bethlehem has funded research at untversicies in collaboration with NSF. 


\section{INDUSTRY APPROACH TO GENERIC TRIBOLOGY R\&D}

A. Quantitative Estimates of Generic Tribology R\&D by Industry Segment:

\section{General Discussion}

The basic estimating approach has been, first, to determine through visits the overall level of generic $t r 1 b o l o g y ~ R \& D$ under way in individual companies, each of which was considered a "sample" of the segments identified in Section III "Tribology Industry Categorfzation", and, second, to extrapolate data for the individual companies using published information to estimate the total level of effort for the entire industrial segment. The extrapolation is based on the sales of the company visited relative to sales for the industry as a whole, corrected by the ratio of $R \& D$ to sales for the company visited relative to the Industry as a whole.

Th1s approach has 11mitations. Firstly, the categorlzation of the tribology industry of Section III underlying the assessment, while heurfstically valid, does not always succeed unamb1guously in defining industrial segments with individual companies each of which can be treated as a statistical sample. Secondly the industry is so large and diverse that it was not possible within the limited resources available to obtain large samples, although 27 companies were visited rather than 20 as orlginally planned. Thirdly, 1t was not posstble in all cases to obtain enough published information to make posstble a systematic and quantitative extrapolation. Published information is not always available for privately held companies, and the level of detail in the infotmation published by large corporations does not always contain adequate data concerning the subdivision under study.

Despite the limttations of the approach, it has been possible to give, at least, a rough qualitative plcture of generic R\&D In tribology, as well as other related $t r 1 b o l o g y$ R\&D efforts, for each of the 1ndustrial segments; with quanticative estimates that we belleve to be correct to within a factor of two or three. As Indicated in Section V B, below, the qualitative structure of the research is more 1mportant than the magnitude.

\section{D1scussion of Industrial Segments (Table V-1)}

a. Aerospace, Power Plants, S11ding Bearings, F1lters, Sma11 Mechanica1 Products

These segments did not show any generic R\&D in tribology sponsored by industry. Where there is generic work in the aerospace industry, it is sponsored by DOD and NASA. DOE funding for the adlabatic diesel, though directed to tribology, in part, is primarily oriented to development of the engine prototype. There is a significant portion of the total R\&D in these Industries, however, that is devoted to shortrrange "firemighting" problems with tribological elements such as bearings, gears, seals, etc.

b. Liquid Lubricants, Transportation, and Metal Forming

In each of these segments, one company visited has a substantial level of 
effort in generic tribology R\&D. The industry-segment estimate was made by multiplying the figure for the individual company by the following ratios:

Industryowide sales/company sales, and

$R \& D$ expense to sales ratio industry+wide/R\&D expense to sales ratio for the company

Obviously this can only give an order of magnitude. In the case of liquid lubricants, one of the two companies visited did not do any generic research. But the other company (Mobll) was deemed to be more typlcal of the industry as a whole. Again, short-range product+oriented tribology R\&D efforts are substantial at both compantes.

In transportation, the extrapolation was made on the basis of the figures for Ford, rather than for Chrysler (which indicated no generic R\&D in tribology in 1982, although tribology $\rightarrow$ related product fire-fighting was quite evident).

Bethlehem Steel was the only representative of the metal forming industry. Thus the estimates shown can be considered significant only in order of magnitude.

c. Seals, Gears, Solid Lubricants and Coatings

An estimated $\$ 1 \mathrm{M}$ level of effort $1 \mathrm{n}$ each of these categories was based on the strong showing of one of the companies in each of these flelds. Short-range tribology R\&D is much higher, of course.

d. Ceramics

Each of the ceramics companies visited had small ( $\$ 1 M$ ) level of effort in generic tribology R\&D, but larger shortrrange product efforts related to tribology. The 1ndustrywide figures assume that between one-half and onerfourth of the ceramics Industry was "sampled"

e. Rolling Bearlngs

It was not posstble to make a systematic estimate of the total level of generfc and shortrrange tribology R\&D for the rolling bearing segment of the industry. Detalled quantitative information on generic research in each of the companies was limited, and published information was also restricted. Nevertheless, it was possible to make a judgment based on information elicited in the visits and on the long experience of one of the authors with this industry.

\section{B. Observattons:}

There is more consistency in R\&D practice w1thin an industry segment, represented for example by ratio of $R \& D$ expenditure to sales, than there seems to be across segments. Despite a great deal of "scatter" In the data, a pattern does seem discernable for most industries, and a rough quantitative representation of the tribology industry is indicated in Table V-1. In some cases there is a bimodal kind of varlation within an industry. For example, 
In the rolling bearing and solid lubricants/coatings areas, some compantes appear to have a speciflc generic research activity, and some do not, although all do short-range fire-fighting in tribology.

In some respects, there is likely to be more generic research activicy than is seen on the surface. This would be represented by the design manuals used by the Individual companies. Such manuals tend to represent the compllation and distillation of much experience in the fleld and from many short-range efforts. In some cases the data are organized by statistical correlations, and in some cases there are theoretical curve fits. The latter are really the key products of generlc research. Unfortunately, however, much of the design information for an individual company is considered proprietary so that 1 ts effect on advancing the state of the art tends to be slow.

Except for the limited $1 \mathrm{n}$-house activities referred to above, as Table $\mathrm{V}-1$ Indicates, there are some tribology industry segments where there is little or no generlc research. Even when there is a definable canpany-sponsored activity in generlc research, it does not always reach a "critical mass" so that significant results are produced to advance the state of the art. Complete and well integrated outputs are more frequent where the budget for generic research is substantial, as in the liquid lubricant and transportation industries. In the ceramics area, for example, it is doubtful that the relatively small and scattered increments of research can produce a significant useful body of information very soon, whether for the individual company or for the industry as a whole.

Even the larger expenditures on generic research are rather small in absolute magnitude, very much smaller than the large sums publicly quoted as R\&D expenditures would 1ndicate. Benefits to the state of the art on an 1ndustrywide basis, and hence competitiveness of American with foreign industry, are reduced by the scatterling of resources and unnecessary duplication. This suggests that fostering the institutions that encourage cooperation in generfc research may be more valuable to industry than direct government expenditures on R\&D.

The role of ECJT expenditures, which are small compared to DOD, NASA, and hardware program expenditures, must be viewed in this light. Firstly, it is evident from Table $V+1$ that there are some generic tribology industry segments where annual ECUT expenditures on the order of $\$ 1 \mathrm{M}$ w111 be From 20 to 50 percent of the total. Ceramics is one of these, so that substantal benefit would be felt under any conditions (provided the research were truly generic and not an adjunct to the relatively well funded work on materials and adiabatic diesel components). But even in ceramics the 1mpact of the research could be multiplied greatly by leveraging government funds with industry cooperation. The role of coordination with government and cooperation with industry is discussed in Sections VI and VII. 
Table V $\div 1$. SUMMARY OF R\&D TYPES AND ESTIMATED GENERIC TRIBOLOGY R\&D IN THE TRIBOLOGY INDUSTRY

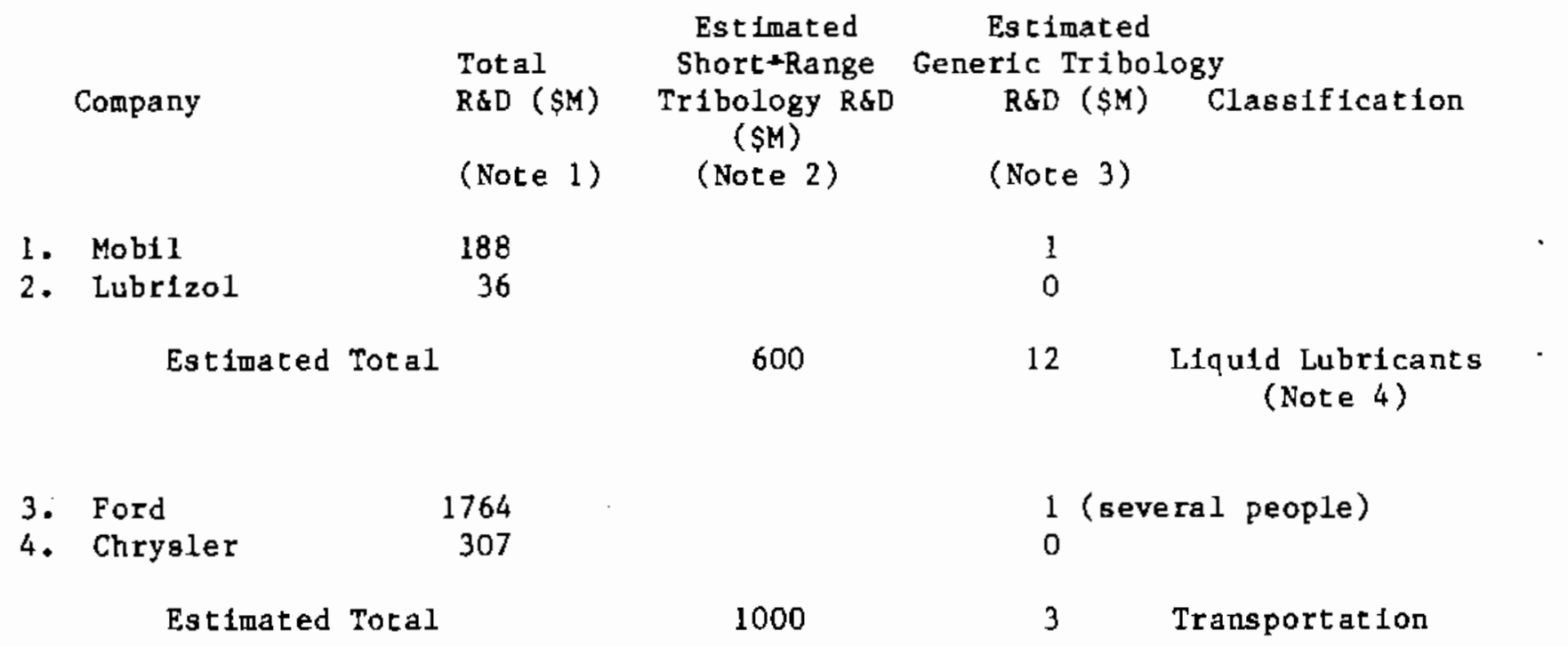

5. Pratt and Whitney 835 (UTC)

6. Williams International

7. Hughes

0

0

Estimated Total

800

Aerospace

8. Caterpillar

0

9. Cummins

54

0

Estimated Total

$400 ?$

0

Power Plants

10. Crane

10

$<1$

Est Imated Total

20

$1 \quad$ Seals

11. Federal Mogul

12 (90 pers.)

$2 ?$

12. SKF

13. TRW

109

$>0$ ?

Estimated Total

$300 ?$

$10 ?$

Rolling Bearings

14. Western Gear

15. Eaton

100

0

$>0$ ?

Estimated Total

$200 ?$

1? Gears

(Continued on Following Page) 
Table Vi-1 (Contd) Summary of R\&D Types and Estimated Generlc Tribology RóD in the Tribology Industry

\begin{tabular}{|c|c|c|c|}
\hline & Total & $\begin{array}{l}\text { Estimated } \\
\text { Short+Range }\end{array}$ & $\begin{array}{l}\text { Estimated } \\
\text { Generic Tribology }\end{array}$ \\
\hline Company & $\begin{array}{l}\text { RSD }(\$ M) \\
(\text { Note } 1)\end{array}$ & $\begin{array}{l}\text { Tr1bology R } \& D \\
(\$ M) \\
(\text { Note 2) }\end{array}$ & $\begin{array}{l}\text { R\&D (\$M) Classification } \\
\text { (Note 3) }\end{array}$ \\
\hline $\begin{array}{l}\text { Copper Dev, } \\
\text { Tribon }\end{array}$ & $>\begin{array}{l}0 \\
0\end{array}$ & & $\begin{array}{l}0 \\
0\end{array}$ \\
\hline
\end{tabular}

Est1mated Total

18. Pall
7

$30 ?$

Sliding Bearings

Estimated Total

$20 ?$

0

0

Filters

19. Xerox

565

20. Black \& Decker

30

Estimated Total

200

$>0$

0

0

Small Mechantcal

Products

21. Carborundum

22. Norton

26

23. GTE

267

Estimated Total

$150 ?$

24. E-M Lube

25. Hohman

26. Union Carbide

Estimated Total

27. Bethlehem

Estimated Total $\begin{array}{rl} & 6 \text { (Great Lakes) } \\ <1 & 1 \\ 240\end{array}$

$300 ?$

46

100
4? Ceramics

4? Ceramics

$<1$
$<1$
$<1$ 


\section{PROGRAMMING GENERIC TRIBOLOGY RESEARCH TO MEET REQUIREMENTS OF INDUSTRY}

A. Introduction:

1. Objective: Developing Plans for ECUT Gener1c Research Program

ECUT supports generlc research so that the results of the research can be used by private Industry to improve or develop new commercial products, and to increase productivity of private industry. ECUT concentrates on technology for the conservation of scarce fuels, but in ther respects its objectives are essentially the same as those of research managers in private industry.

In this context, research results themselves are not considered as commercial products. They are an input to industry, not an output. That is a key assumption in Section VI, the purpose of which is to suggest some planning guidelines, and to lllustrate thelr application in some specific tribological research areas.

This section has been organized hierarchically, golng from general concepts to specific applications. It is very useful to consider the process of planning in a general way, since many 1mportant aspects of planning are reasonably stable, while technical needs and speciflc research tasks change more rapidly. The general discussion is illustrated throughout by comments on specific technical 1ssues; and applied in Section VI D to the task of "Relating Laboratory Characterization and Testing to Performance" in two spectflc areas, liquid lubricants and ceramics.

\section{Distingulshing Between Producers and Users of Research Results}

USERS of research results, that is industry as defined above, have to be distinguished in the present context from the PRODUCERS of research results. Defining the relationship between producers and users of research is important because their interests, though complementary, are different. The relationship is like that between the interests of the buyers and sellers of any product, because research results are, themselves, products. There are many conmercial, and not-forrproftt organizations in business to produce and sell research results to customers in goverment and industry. Even universities at which englneering research is carried out may be thought of as businesses that have research results as a product.

To be useful the research results have to be 1ntegrated into a package that the user can assimilate. The effort required in packaging, and the nature of the package will depend upon the users. Sophfstlcated technologists may be in a position to apply scattered esoterlc scientific information to their speciflc needs. But the prevalling attitude among engineers contacted during this assessment was that more research was being done than was being used.

The problem is not only to assemble valid data and make it accessible. One example of this was in the use of the "ASME Wear Control Handbook." Inquiries disclosed that this handbook was rarely used by designers and developers in 1ndustry, although $1 \mathrm{t}$ had been produced for the1r benefit and was avsilable at most of the companies visited. It was most useful to the most sophisticated 
technical people, with the greatest value of the material in the "ASME Wear Control Handbook" being for the spectalists in tribology, such as those who contributed sections to this volume.

Different Interests of the commun1ty of users of research results, and the community of producers are manffested in choosing the subject of the research, and in evaluating the integration of the research package. The researchers and consultants who produce research results are also "users" in a sense (but the only product they produce is more research results). They tend to work at the leading edge of technology; and are therefore more interested $1 \mathrm{n}$, and readily able to assimilate scattered and esoteric research information. Therefore research that strengthens the ability of the research producers to do their job better will not usually require speclal integration or packaglng. Conventional "peer review" procedures are appropriate in evaluating research efforts at this level. But funding that is geared to benefit the community of research producers will not necessarily satisfy ECUT's objectives.

\section{Funding Producers of Research Results to Support Users}

The role of using peer review criteria in supporting the research community is already being filled by NSF and DOE/OER. The1r primary purpose is to provide resources to improve education and to support work on innovations that may be expected to reach frultion in the longer term; their objective is not primarily to make the research community more responsive to the everyday needs of industry. In contrast, ECUT's role is focused more directly on the applications of generic research, with implementation of advanced technology and innovations that will provide economic benefits in the relatively near term. Thus ECUT's interest is in making the producers of research results more, rather than less, responsive to the needs of the industrial users.

To the extent researchers are funded by the goverment they become economically independent of industrial cllents, and their motivation to help industry is correspondingly reduced (although the ability to help may be 1ncreased). Th1s may even be the case when the research organization funded by the government is the laboratory division of a company that manufactures and sells material products as 1 ts primary business. The avallability of the corporate laboratory's resources to its engineering department is diminished to the extent the laboratory management is responsive to the goverment funding agency. For these reasons some industrial managements do not allow, or severely 11m1t, their corporate laboratorles' acceptance of government contracts. Of course, properly managed, the government support can be beneficlal, but a favorable effect is by no means automatic.

\section{Basic Requirement}

It is evident from the above that when ECUT funds producers of generic research results to 1mprove the quality of commercial products and industrial productivity in the relatively near term, the task is complex; there are many pitfalls and opportunities to be counterproductive. The task of planning a program to benefit industrlal users of research results involves more than the questions of technical excellence that may be answered through peer review. 
Other criterla and procedures have to be used.

One requirement is outstanding: It is essential for research results to be read1ly useable by those for whom they are intended. The present assessment has shown that in many important cases of interest to the tribology community and to ECUT, fragmentary research results cannot be assimilated well by Industry. These results have to be assembled and integrated into a package that can be used readily by the development and design engineers. If there are delays and other costs in applying new results they will be used less frequently, and the advance that is being sought in the state of the art will be slowed.

Therefore it is essential for ECUT to bulld the technical bridges that will speed application by Industry of the most sophlsticated research techniques and ideas. In many cases this bridge building will push the state of the art beyond its present limits, and in other cases apply the existing state of the art in a sophisticated way.

\section{Guldelines for Planning}

The following section (VI B) presents a description of the applications of gener1c research in terms of the needs of Industrial users of the research results. When considering research results in terms of these applications, it is more readily apparent that scattered, esoterlc research profects cannot serve industry we11, and that integrated packages are required.

Section VI C discusses the elements of an integrated research package for application to industry. These elements are categorized in terms of the scale of the phenomena being considered, and in terms of the disciplines involved. To serve in the applications described in Section VI B, it is evident that a broad range of these elements are needed to construct an integrated package.

Section VI D relates the discussion of the sections preceding it to specific tribology research and development issues: "Relating Laboratory Characterization and Testing to Performance" in the Iiquid Iubricant and ceramics flelds. One observation from Section VI $C$ is that many of the same tribological research elements can serve in more than one integrated application package. Possibilities for taking advantage of the opportunity this affords in assembling cooperative prograns with industry are discussed in Section VII. 


\section{B. Applications of an Integrated Generic Research Package:}

The applications of generic research, described below in Sections VI $B 1,2$, and 3 , are as engineering tools to expedite design and development, so that new materials and Innovative design concepts fostering conservation of scare fuels can be introduced tato the market place and made economically significant. Thus, these applications motivate ECUT sponsorship of generic research. As suggested in Section VI A, not all generlc research will produce the near term effect on conservation and the market place sought by ECUT, and 1 is important for management to focus on speclfic applications such as those set forth below.

\section{Empirical Des1gn/Development}

Emplrical design and development is the traditional approach that is still widely used in mechanlcal engineering practice and therefore deserves the attention of ECUT management. It is displaced more and more by analytical techniques, but where changes in the product are relatively sma11, testing Inexpensive, and there is an extensive "corporate" memory in the engineering department, a cycle of design/bulld/test may well be preferred to an analyt1cal approach. When this is the case, engineers rely heavily on relevant data and on scalling techniques.

Generic research can contribute by producing data with broader relevance and by improving the scaling techniques for making laboratory data, or data obtained in the fleld, applicable to new designs. A simple example of this is in the application of PV (pressure times velocity) data in predicting wear: There are problems about the upper and lower values for $P$ and $V$ at which the magnitude of the product is scalable, organization and extent of the data, and environmental conditions (temperature and partial pressure of chemical species) under which it is taken.

This is typical of many areas where further work that could be useful to industry would challenge scientists. Both theoretical and experimental analyses are required to understand the limits of existing data, to improve the planning and control of expertments, and to increase the range of applicabilicy of emplrical data through fmproved scaling techniques and qualitative insight. The need is not for more data but for more information. In the application to empirical design and development, as in the more sophisticated applications discussed in the following sections, research directed simply to improved physical understanding may well be useful, if it is well integrated 1nto a package designed to be useful to the engineer doing design and development.

\section{Mathematical Modelling}

Mathematical modelling is at the center of advanced technology for design of products and processes. The objective is to design on paper (or on a computer display) so that the expense and delay of extensive "Edisondan" trial and error can be avolded. Although this ideal is seldon, if ever, reached, mathematical modelling does expedite design and development. Computer optimization of design parameters is facilitated, permitting a broader 
examination of alcernatives and more rational decistormaking in design. There is probably no area of mechanical engineering, new or craditional, that cannot benefit by the more extensive application of mathematical modeliing.

Development of mathematical models requires sophisticated coordination of experimental and theoretical analysis. Additional care is needed to ensure usefulness to design and development englneers. There is a critical need for documentation of the model and the computer code. Th1s step is of ten neglected so that only the model's developer has access to it; and it is almost worthless to others, even the most sophisticated potential users.

In general, facilities for access to the mathematical models have to be matched to the user's needs and level of understanding. Interactive, "user+friendly" computer programs are an attempt to make sophisticated analysis more widely accessible. Substantial investments to increase accessibility may well be appropriate to make the investment in the generic research pay off. An integrated generic research program will balance the need for the generic research results and the need to make them accesstble.

\section{Testing Technology and Standards}

Innovation and responsiveness to markets in developing and designing new products depends upon belng able to configure new and exlsting materials and components in different ways. Firstly, this depends on the capabilities provided by che empirical design information and mathematical models discussed In the two preceding sections (VI B 2 and 3). Secondly, 1t depends upon reliable ways to characterize materials and components avallable to the designer.

Testing technology and standards are the basis for this second capability. This includes techniques ranging from microscoplc characterization of surface roughness; to macroscopic pin+on-disk, rolling contact fatigue, and fourtball tests; to tests of components and products such as the 5 -car economy tests. Testing technology and standards depends upon the same research information required for the development of empirical design data and mathematical modelling. In addition, developwent of testing procedures, and test apparatus is required. The objective is economical and reliable techniques for predicting performance and lifetime of the product.

Speciffcations and tolerances on materlals and caponents not only determine the performance and life of the end product, they also determine costs. To minfmize costs subject to constraints on performance and lifetime, it is necessary to take into account the effects of changing specifications, and of tolerating variances. In some cases engineering practice has been based on standards that have been too conservative to be economical; and in some cases economic competition has led to unconservative divergence from traditional standards with disastrous results. Avolding both extremes requires the kind of Information that is produced by generic research and reflected in the establishment of effective testing technology and standards.

Non-destructive evaluation and quality control are also an element of testing technology and standards, and extremely important for technological innovation 
and productivity. Whether it is possible to realize the potential from using a new material or process for product improvement will of ten depend upon whether 1ts quality can be controlled and measured economically.

Depth of understanding that can be provided by generic research is essential to economical quality control. The effects of varlances from specifications (e.g. surface defects or voids in coatings or ceramic parts) have to be understood so that a tolerable rate of occurence can be determined; Instrumentation and procedures have to be developed for economical nontdestructive evaluation; and a basis for setting standards defined. In many ways quality control is the most demanding application for generic research: a broad range of empirical data is required for validation; understanding of the phenomena in some depth is desirable, if not essential; and some analytical tools, mathematical models at some level of detall, are required to relate parameters measured by the quallty control apparatus to the operational characteristics sought by the manufacturer and his customers. This information may also be critical to the material developer in doing cost-benef 1 t tradeoffs on process development. 


\section{Elements of an Integrated Generic Research Package:}

The purpose of this section is to form a sort of check list that will ald the manager in ascertaining that the research plan is complete and includes all of the elements required to form a useful integrated package. These elements are broken down in terms of two, essentially orthogonal, categorles, scale of the phenomena (Section VI C 1) and research approach (Section VI C 2). Scale of phenomena is broken down further into component, macroscopic, microscopic, and atomic/molecular categorles; and research approach is divided into theoretical and experimental analysis categories.

It will be evident that applications discussed in the preceding section require results derlved from work in many categorles of generic research integrated into one package. As pointed out in Section VI A, fallure to provide an integrated package will severely limit the usefulness of generic research; and will in some cases produce results that are counterproductive in terms of ECUT obfectives.

$$
\text { 1. Scale }
$$

\section{a. Component}

This research area defines the conditions under which a mechanical component is operating within a machine. For example, the velocities, loads, temperatures, and partlal pressures of the chemical species characterlzing the environment or "boundary conditions" for a piston ring or cam-follower in an engine. In some cases, e.g. some gear train applications, the kinetics analysis may be well understood and routine; but in the piston ring example noted, the picture is much less clear and addittonal research may be required if piston ring friction, wear or seal performance is an issue.

The importance of the chemical spec1es surrounding the component has been well known for a long time, but it is relatively recently that the subject has been approached in a systematic way. In some cases the ambient atmosphere is well known. In other cases, notably in engines, the problem becomes more challengling, and can be vlewed hierarchlcally: At the zeroth level, elther the combustion products or the equilibrium concentration of the lubricant vapor species form the environment; at the first level, which begins to approach a representation of the actual conditions, the two components mix with the concentrations at any point depending upon the quality of the piston ring seal as well as the diffusion and convection processes involved; at the second level, the foregolng species are jolned by spectes formed through chemical reactions of the gaseous spectes with the surface and the wear debris.

To be complete, the tribological analysis of an engine must deal with coupling between the tribological and chemical phenomena. This situation is reasonably well understood at a qualitative level, but the quantitative analysis has hardly begun in a systematic way. As Peterson has noted, the abilicy to understand and predict lubricated wear is poor. (Personal communication: Notea for paper presented at ASLE meeting May 1984). One of the reasons is that the coupling between chemistry and tribology is not dealt with 
effect 1ve1y.

Two decades ago, dealing with the chemistry and heat/mass transfer problem, even without the tribologlcal coupllng, would probably have been beyond the theoretical analysis capability of the mechanical engineering community engaged in engine development. This is no longer the case, although the problem is still a reasonably challenging one. In any case, if the objective is to improve understanding of friction and wear of engine components, one of the tasks is determining the species forming their chemlcal enviroment. As d1scussed below theoretical and experimental methods of analysis are avallable; and if a predictive ability is sought for varying geometries and chemical species, both theoretical and experimental methods will be needed.

Results of these analyses will bear on development of lubricants and additives, and the relationship between frictional losses and wear. Automotive and lubricant producers expressed concern about this problem in the course of the discussions carried out under this study (See Section IV). In the discussion at Chrysler there was a specific comment that soot absorbs zinc thlophosphate additive, and there is a need for a chemical system not absorbed by carbon; and not poisonous, as phosphorus 1s, to catalytic exhaust converters.

As useful as the qualitative Insight from the understanding of the chemistry 1s, the need for quantitative estimates remains substantial, because the key 1ssue is the RATE at which the key reaction occurs. If the car goes 100,000 miles tefore the zinc is absorbed by the carbon, the problem is much less severe. This rate depends not only on the combustion products, but aiso on the effectiveness of the piston ring seal, the effect of geometry on heat and mass transfer, as well as on the chemical kinetics reaction rates.

The same issues arlse in advanced, sumpless engines where replentstment of lubricants may be achleved by deposttion to the tribological surfaces of species derived from combustion products or fuel and lubricant additives. For such ergines the heat and mass transfer of these spectes assumes the same importance as the distribution of liquids in designing the lubrication system for conventional engines. Suitable design practices and techniques will be required. Capability for predicting effects of chemical reactions coupled with heat and mass transfer throughout the whole engine will certainly be a valuable tool. Developing this capability would be considerably easier than the combustion model development now under way, and comparable in difficulty to various chemical engineering analyses.

To some extent, work at the component level may be useful by 1 tself in some cases, and may not depend critically on integration with other research results. This is because information at the component level can be transferred directly into design. It w111 be much less frequent that research results at a smaller scale, such as those discussed below, will be useful without: information about the environment of the component of which it is a part. Nor will it be possible to carry out meaningful research at the macroscopic level discussed in the following section without knowing the mechanical and chemical environment. For theoretical analyses at the smaller scale, macroscopic level discussed below, information at the component scale 
represents the known parameters, "xlght hand sides" and boundary condtions for the differential equations involved.

\section{b. Macroscopic}

The macroscoptc level is characterized by continum behavior of fluids and solids, and deals with a small segment of the surface of a larger component. The characteristic dimensions of the surface segment are very large compared to surface roughness, but small compared to the camponent of which it is a part. Typically, the macroscopic regime, as defined hereln, deals with a surface segment of a machlne element over which load, speed and other conditions are uniform, or vary in a simple way, in the direction tangential to the surface. The condtions nomal to the surface, e.g. the near surface and subsurface stresses, may vary a great deal.

Macroscopic phenomena would include the segment of a geartooth at a fixed distance from the pitchline, a segment of a roller or ball bearing, ring, cam or cylinder wall. In each case the dimensions of the segment are smatl enough so that conditions determining 1 ts behavior can be specified simply, and large enough to be much greater than surface roughness, and so that continuum mechanics can be used for analysis. The load, speed, and other conditions for the element are determined from the kinetics of the component (1.e. from the component scale of phenomena discussed $1 \pi$ the preceding section.)

Macroscop1c research by this definition is the realm of the pintomedisc, the rolling contact fatigue and other testing or theoretical techniques that deal with an element of the surface of a machine component. For example, EHD is in the wacroscop1c scale, if roughness is characterfzed by aggregate parameters for helght and shape. When EHD analysis deals with the deflection of asperities as individuat elements, it $1 \mathrm{~s}$ conventionaliy referred to as micto-EHD, and is also considered as being at a "microscopic scale" in this discussion (See the following section).

The chemical spectes are also considered to be uniform over the surface in the direction tangential to the surface at the macroscoplc level of phenomena. Typically, these species may vary normal to the surface, possibly in the manner of a boundary layer. Conditions at the outer edge of this boundary layer are determined from the heat/mass transfer and chemical reactions analysis determined at the component level.

It will be clear that there is a mutual interaction between the component and macroscopic levels of phencmena. For example, the friction and wear on an element cannot be determined unt11 the load and speed is determined; but the load and speed at a given throttle setting cannot be determined until the friction is evaluated and integrated over the entire surface it while the allowable speed w11l depend upon the wear rate that corresponds to an acceptable lifetime or time between overhaul. There is also an interaction between the heat/mass transfer chemistry and the mechantcal phenomena at the macroscoplc, as well as at the component level as discussed above. 
For example, an analysis of the phenomena in a pintomdisk test might attempt to calculate the loss of surface oxide as a result of rubbing, and the replentshent of the oxide due to chexical reaction with its environment. Conceptually, the loss mechanism would incorporate parameters for normal load (e.g. Hertzian stress), tangentlal load (e.g. friction coefficlent), velocity and possibly others; while the replentshment mechantson would depend upon temperatures, partial pressures, and transport coefficlents for the species Involved. A long lifetime for the surface would require the replenishent rate to exceed the loss rate from wear.

Parameters or relationships derived from theoretical or experimental analysis of the microscopic phenomena discussed in the following section might also be incorporated; among them results of statstical analyses dealing with non $u$ iformities in the surface, analagous to those in rolling contact fatigue iffetioe estimation. It is possible that replenishment at some surface localitles may not equal the 108 s even when the average replentshment rate is adequate on the average.

Conceivably, 11quid lubrication could be treated in an analogous way, with the 11quid being the mass transport medium for the chemical species. The same approach would apply to any chemlcal system. In each case, the approprtate transport and chemical rate coefficients would have to be estimated from suitable experiments or theory.

There are many examples of experfmental and theoretical analysis of macroscopic phenomena, but they all have one common characteristic: to be of practical engineering use, they must use inputs derived from the component scale cf phenowena. Therefore, for the application of generic research, macroscopic and component level phenomena have to be assembled into an integrated package.

\section{c. Microscopic and Atomic/Molecular}

Microscopic analysis is the regime for analyzing the behavior of discrete rougness elements. Continuum mechanics may represent some of the phenomena, but must be used with caution, and atomic dimensions are approached. For the purposes of this discussion, the largest scale is considered to be about 1 micron and smallest about 0.01 unicrons.

At the lower bound $1 \mathrm{t}$ would be reasonable to characterize sma11 roughness elements, say by dividing roughness elements 1 microlnch or 0.025 microns in size, into segments about onetenth as large. This will still be dealing with dimensions about 10 times that of atoms; but a "finite element" analysts of roughness elements much smaller than one microlnch would involve atomic dimensions. The approach to atomic dimensions may be critically important in the analysis of dry contacts when oxides or other coatings form the lubricant.

With wet contacts, there may be some difficulties in characterizing a liquid as a homogenous entity at this scale, egpecially when additives are involved. For example, at the meeting with Mobil there was an allusion to the gradient 
of constituents across the 1iquid layer in EHD contacts. Rheology may have to deal with the nonrcontinum aspects of this regime. W1th gases it 1 s clear that continum mechanics must be used with caution. For example, the mean free path of atmospheric molecules is about 0.06 microns at sea level so that for roughness elements significantly less than a micron at sea level continum gas dynamlcs, i.e. the Navier Stoke equations, do not give a good representation of transport phenomena.

The role of the microscopic regime in a program of generic research for ECUT depends upon whether the results of microscop1c analysis can be integrated into a package applicable to engineering problems. This can only take place if results of the microscoplc analysis can be applled in the macroscopic regime discussed in the preceding section. There are many opportunities for this to take place, but the integration of macroscopic and microscopic results is not necessarily automatic, and will ususlly require attention and skill on the part of the technical program management.

Typically, microscopic analysis will be useful to develop inputs to macroscopic calculations. For example, in the estimation of wear lifetime discussed in the preceding section, both the loss and the replenishment rates will benefit from analysis in the microscopic regime.

For example, it may be posstble to estimate loss rate as a function of 1 oad and speed by estimating the frequency of asperity contacts, and the rate of fracture or deformation on a statistical basis. Such analyses, even if they do not yleld results that are quantitatively correct, may reveal the functional relationshtp for relevant parameters such as roughness helght and shape, and material hardness.

Information of this kind is invaluable for developing semiempirical correlations and scallng laws. Such scaling laws can be tested by how well they can correlate empirical data. Thus microscopic analysis may be as important to the relatively unsophisticated designer using empirical data for design and development as to the more sophisticated engineer using mathematical models. The research manager has the responsibility for ensuring that this relevance exists and is used effectively.

Replentshment rate al so requires microscopic analysis as an input to the macroscopic calculation. Typlcally, this analysis requires unfolding chemical kinetics rate constants from the viscosity and diffusion coefficients governing mass transport. In the region within a few mean free paths of the surface, and whenever the scale of the phenomenon does not adoit a continum approximation, a microscoplc analysis is required.

An understanding of scuffing failure Initiation is also likely to motivate microscopic analysis. This view is well represented by $L$. D. Wedeven (formerly of NASArLewis, currently SKF) 1n an Informal paper "Concept of : Jolnt Program on the Trlbology of Load Capacity. Wedeven recommends that for fallure prediction it is necessary to consider "...surface topography, micro + EHD, surface films, lubricant chemistry, and near surface plastic flow...." He also suggests an integrated program to predict load capacity and the conditions leading to scuffing. 


\section{Research Approach}

The preceding sections show that generic tribological research is carried out in component, macroscop1c, microscop1c, and atomic/molecular scale regimes; and that to provide an integrated package of research results sultable for application to englneering problems, all the regimes have to be considered. The purpose of this section is to emphasize that for each regime, two research approaches are avallable, theoretical analys $1 s$ and experlmental analysis; and that unless the program effectively integrates both approaches, widespread usefulness in englneering applications is doubtful.

This integration between theoretical and experimental results also applies when the primary application of the generic research is Emplrical Design and Development as discussed in Section VI B 1. For example, the usefulness of experimental results for wear to predict lifetime depends on the qualitative understanding of the phyalcal processes as well as on the data base. This qualitative understanding 15 reached through a broad range of diagnostic experimental techniques such as electron microscopy for visualization of the phenomena, and theoretical analysis.

In almost every case theoretical and experimental analysis have to be carried out in conjunction with each other. Theoretical analysis is rarely useful if unconfirmed by experiment; and experimental results uncorrelated by theory, or without a basis for scaling between laboratory and engineering application, have very limited usefulness. 
D. Relating Laboratory Characterization and Testing to Performance:

This section discusses application of an integrated package of generic tribology research (See Section VI A) to testing technology and standarda (See Section VI B 3) In two specific areas, liquid lubricants and ceramics. The motivation for choosing each of these areas is discussed in the following sections along with some technical aspects of the research requirements.

1. Liquid Lubricants

a. Motivation

The most fmportant reason for generic research in tribology applied to laboratory characterization and testing of liquid lubricants is the widespread impact in industry. Wedeven*, who is primarily interested in load capacity of high performance gears, has expressed very well the limits to innovation that generic research is supposed to overcome as follows: "First, it 11mits the ability to predict performance so that 1mprovements can come about more through numerical simulation rather than hardware iteration. Second, it Ifmits the abillty to establish a realistic load capacity criteria so that reliable test devices can be developed to evaluate new opportunities. Third, it limits the sclentiflc base which, along with a rellable test device, is needed to strengthen Innovation and encourage the development of new 1deas."

Inpacts of a well 1ntegrated program applied to testing technology of liquid lubricants will be felt not only in understanding and predicting scuffing fallures and acceptable load capacities for high-performance gears, but in other areas that were discussed during the course of this assessment. The most direct effect, perhaps will be on developers and users of lubricant additives such as Mobil and Lubrizol.

Both flrms stressed the 1mportance of testing technology and pointed out that the goverment could have a favorable impact on fuel conservation through more widespread use of additives to reduce frictional losses: There is a need to support the rellability and credibility of additive manufacturers' clatins that excessive wear or other new modes of failure will not occur as a result of the changed viscosity characteristic. The credibility added by the government participation might be as significant as the funding. Automotive manufacturers will also share in this benefit if the tradeoff between wear and friction, mentioned durfing several visits, could be understood and predictions made on a rational basis. As Peterson has noted (See Section VI C 1 a), some effective lubricants are avallable, but wear mechan1sms are unclear, test methods inadequate, wear control impossible, and effects of additives unpredictable.

* "Concept of: Jolnt Program on the Tribology of Load Capactty," informal paper. See also Section VI C $1 \mathrm{c}$. 
Filtration is another area considered in this assessment that will benefit fron development of improved testing technology for liquid lubricants. An integrated program cannot overlook the chemlcal and mechanical effects of wear debris and other species subject to filtration that were discussed durfng the visit to Pall (See Section IV), and considered further below. The potential for cooperative research support from the public and private sectors will be enhanced by effective consideration of filtration, which is mandatory on a technical basts in any case.

There was also substantial interest in surface fintsh cesting and standards shown during the present assessment by Caterpillar representatives and others; and a need for goverment support or cooperative research since it is Impossible for a single company to recover expenses for a full program. Surface finlsh might be considered as a separate subject, but it would have greatly diminished technological 1mpact, and could not be considered to be a we11 integrated program if the Interaction with lubricants were omitted.

Other areas may also be 1nvolved. For example, during the meeting at Pratt and Whitney, their representative expressed concern about the incidence of early ball fallures in maln shaft bearings. Effects of lubricant on fatigue might well be incorporated into a program relating laboratory characterization and testing of lubricants to performance in the fleld. In any case, a well integrated program of generic research should disclose new facts and ideas with effects beyond those planned for.

Generic tribology research to relate laboratory characterization and testing of liquid lubricants to performance in the fleld requires an integrated program with consideration of the elements discussed in VI C. Component, macroscopic, microscopic and atomic/molecular scales must be considered usting theoretical and experimental modes of analysis. From the point of view of the ECJT program management, the key issues to be considered are which technical areas should recelve the greatest emphas1s, which areas are being funded (or might be funded) by government or private sources outside of ECUT; and is an integrated program feasible within the timescale and resources available, or potentially avallable. The coordination with other goverment programs, and the cooperative funding of generlc research programs by industry, is discussed in Section VII.

It is evident from the analysis of section $V$, that two of the key industries Involved, automotive and liquid lubricants, already make a substantial investment in tribology R\&D, so that the additional ECUT funding is likely to constitute a small fraction of the total effort. But it is also shown in Section $V$ that the expenditure on generic tribology research in the powerplant, and filter industry is essentially zero, and there is no evidence that any of the research efforts, for example the surface characterization work at SKF under DOE/OER sponsorshlp, are in any way integrated or focused. Therefore, the goverment contribution might well be in filling in gaps that will lead to integrated coherent results, and helplng to focus the generic cechnical work in key areas.

The broad applicability and diverse technical work involved merits consideration of government support for this work. The large effort already 
under way, and the diverse interests require that it be carefully planned. Some of the technical considerations are discused below.

\section{b. Some Technical Considerations}

It is convenient to follow the approach of Section VI $C$, and consider the research requirements in terms of the scale of the phenomena. At the component level, the chemlcal environment of engine lubricants and lubricated surfaces has not been well characterized within the present state of the art (Section VI C l a). As a consequence there 18 no systematic and controlled testing procedure or equipment to deal with this phenomenon. Remedying this lack may well be take a high priority in planning.

This is not necessarily to say that further support for the mechanical component level research should not be consldered, but only that there has been more progress in those areas with further effort planned by industry. For example, Mobil is carrying out tests on a fired engine and the kinetics of piston ring behavior has been recelving falrly extensive attention. In his informal paper on scuffing and gearbox load capacity alluded to above, Wedeven indicates that what he calls the "global aspects" are on good quantitative grounds. He also belleves that a good start has been made in work on the individual characterization of surface topography, micro-EHD, surface films, lubricant chemistry, and near surface plastic flow. He goes on to say, "While there is a great deal of information on these individual constitutive parts, their Interactions in a real system are mostly unknown."

In terms of the present circumstances, this conclusion might be interpreted as follows. Particular conslderation should be given to coupling of the chemical enviroment effects across the three levels as discussed in Section vi $\mathrm{C} 1 \mathrm{a}$, since there has been relatively little quantitative attention to this area in the past. This will require integrating results of the wicroscopic analysis into the macroscopic research, and relating results of the macroscoptc research to behavior at the conponent level that is measurable and significant to producers and customers.

The macroscopic and microscopic areas are relevant to a broad range of users concerned with testing technology and standards; and work in these areas is sparse and scattered. Careful plans are needed to fill gaps and ensure that the results of the research are accessible to these users. Two relevant 1ssues were identifled in the course of the present assessment: characterization of surfaces, and presence of debrls and contaminants whlch may be affected by filtration.

Some aspects of the filtration problem are discussed in VI $C 1$ a, and some were discussed in the visit to PALL (See Section 1V). Among the issues are the possibility that some of the smaller particles were more damaging than larger ones because of catalytic chemistry, and the role of various solid and liquid contaminants including water and other solvents, aclds, chlorine compounds and salts. 
Another relevant consideration in this context is the issue of surface characterization, whlch was mentioned during several visits, and recelved the greatest emphasis durlng the discussion at Caterpillar (See Section IV). It Is clear that in addition to the roughness height specification used in conventional practlce, other parameters must be considered in specifylng surface finlsh. A technology of measurement, and system of specifications covering lay, slope, and perhaps, some higher order definttions of shape are required.

Filtration and surface characterization are both coupled with the laboratory characterization and testing of Iubricants to determine their functional performance. There 1s no way that the lubrlcants can be spectfied on a rational basis without specifying the environment and the surfaces with which they are in contact. Thus, an integrated generic research program relating functional performance of liquid lubricants to their laboratory characterization and testing also has to 1ncorporate collateral work on laboratory characterization and testing of filters and surfaces. 


\section{Ceramies}

\section{a. Motivation}

Ceramics for trlbological elements are on the threshold of becoming a major commercial activity. For example, the May 1983 1ssue of the "Ceramics Bulletin" projects an annual market of $\$ 1$ to 5 Billion if there is a limlted replacement of metals by ceramic elements in engines. With greater use of ceramics, the projected market approaches $\$ 30$ B1llion. This estimate is supported by information obtained during the present assessment. Many companies, Including Ford, Chrysler, and Pratt \& Whitney are seriously considering the use of cermics. The most recent report of the increasing interest in ceramics, whlch stressed the effort in Japan, was on page D1 of the May 24, 1984 issue of the New York Times.

A great deal of government and private funding has gone 1nto development of ceramics for eng1nes but, as indicated in Section $V$, the industrial funding of generic tribology R\&D is on the order of $\$ 4$ Million for the whole 1adustry. Th1s effort 1s scatcered; and there is a major opportunity to expedite technological progress by providing the Information needed to make possible a more rational approach, and greater confidence in producing designs and material specifications. It 18 possible that a small, well integrated program of generic tribology research can do more to speed commerclal growth than much larger expenditures devoted to product developnent. Government expenditures on development of commercial products have rarely, if ever, been successful in achieving their afm, whereas expenditures on generic research have had a good record of success.*

\section{b. Some Technical Considerations}

The approach to a program relating laboratory characterization of ceramics to functional performance is very similar to that for the corresponding liquid lubricants program. The maln differences are a greater emphasis on solid lubricants, and on the spectal problems of characterizing ceramics.

Beglnning wth the component level, the same comments on the mechanical and chem 1cal areas of research apply as in Section VI $D$ l b. The chemlcal environment for ceramic surfaces 1s, of course, especially important for a varlety of reasons.

* Th1s point 1s well documented by various studles. An excellent, fairly recent source is "Government and Technical Progress: A Cross-Industry Analysts", Richard R. Nelson, Editor, Pergamon Press, New York, November 1982 . 
Firstly, the extenslve practical background accumulated with ofl lubricated metals is no longer applicable; and the ceramics industry w1ll not walt another hundred years untll it is reproduced. There is no sound alternative to a rational approach. Secondly, at the higher temperatures that motivate the use of ceramics, there is likely to be a heavier dependence on the chemical enviroment for surface replenishent, a phenomenon mentioned briefly in Section VI C 1 a. As noted there, the heat and mass transfer of the replentshment spectes assumes the same Importance as the distribution of liquid lubricants in conventional englnes.

The problem need not (and probably should not) be attacked from first principles; but there is an extensive armamentarium of theoretical and empirical eng ineering cools available in chemical engineering and gas dynamics disciplines that can produce timely scientific and practical results. It should perhaps be noted that a great deal of the work in this area will be as applicable to liquid lubricated metal as to ceramic englnes. The differences are at the macroscopic and microscopic levels, where chemical spectes of the solid surface and its gaseous boundary layer couple to the engine enviroment.

Characterization and qualfty control of ceramic surfaces at the macroscopic and microscopic levels is an another area requiring emphasis. In practical terms, the need is to learn how to control and interpret tests that are simple and not too time consuming. This involves, in addition to characterizing the chemical enviroment referred to above, characterization of the surface finish. The surface characterization of ceramles also has much in common with the problem assoclated with metals. But whereas there is an extensive technical background in metallurgy and its quality control, the corresponding technology for ceramics is virtually nonexlstent. The significance of the various sizes, shapes, locationa, and frequency of occurrence for surface and near-surface defects must be understood before engineering of commerclal products for a large market is possible. These factors, specific to ceramics, must be: added to the surface finish considerations that pertain to I1quid lubricated metals.

As with 1iquid lubricants, the most appropriate area for emphasis may be in mechanisms at the macroscopic and microscopic leve1; forming and maintaining a surface layer, a problem discussed toward the end of section VI C I b, and others. These have broad applicabllity, and were frequently described by representatives of the companies vistted during the assessment as an area of significance to them. Organtzing and disciplining genertc research in this broad, and as yet rather poorly defined area, will be facilitated if the objective is kept in mind. That is, to control, interpret, and apply routine tests for material characterization and quality control. 


\section{COORDINATION AND COOPERATION IN GENERIC RESEARCH PROGRAM MANAGEMENT}

The programs discussed in Section VI are comprehensive, with all the elements of Integrated generic research included. It is evident that these are very large and complex; and the question artses whether it 15 feasible for ECUT to carry on such an effort. There is reason for doubt. More detalled plans and cost estimates are well beyond the scope of this report; but clearly, the total is almost certalnly greater than the present ECUT budget for tribology. Moreover, effective planning, management and integration of such extensive programs may also require additlonal expenditures for management staff.

The purpose of this section is to discuss brlefly the resources that may be avallable to ECUT in assembling an integrated generic research program in trlbology, and the role it might play in doing so. Potentially, the two primary resources are (I) adaptation of R\&D programs sponsored by other goverment agencies, and (2) Industry funding of cooperative research. ECUT's role might well be first, to provide the impetus and support for integrating the programs so that they form a useful entity justifying the financial participation by industry; and second to fund research that will fill gaps in existing programs and make posstble rounding out an integrated effort.

\section{A. Adaptation of Existing Government Programs:}

The present assessment only considered the generic tribology research being carried out by industry, and found this to be only a small part of the total research underway, but there is a great deal of potentlally relevant research carried out under other goverment auspices. Extensive and detalled information on this work has been assembled under the ECUT sponsored "Assessment of Government Supported Trtbology Programs" by Peterson, which was concurrent with the assessment reported herein. From the report on government cribology programs, it is reasonably clear that the extensive work sponsored by the goverment is not organized as a coordinated response to the needs of industry for generic research results.

As pointed out in Section VI A, much of the work, notably by DOE/OER and NSF, is deliberately focused on the far term, typlcally more than ten years in the future. This work 1s not intended primarily to be responstve to the needs of industry for commercially useful innovation and increased productivity in the next few years as ECUT results are. At the same time there have been programs by NASA and DOD which have been focused on specific hardware applications in the near term. But these are also not readily applicable to Industrial users who require eng1neering information pertaining to other hardware.

None of these programs have intended to produce generic research aimed at the same objectives being pursued by ECUT, but it is likely that they have produced applicable results in some cases. It is even more likely that in many cases it w1ll be more efficient to adapt existing results to ECUT needs than to start from scratch. Even if applicable research is a small fraction of the rotal, it may be important in terms of the scale of the ECUT program requirements.

There has been little effort to glean results for near term application that 
may already have been obtalned from basic studles focused by OER, NSF, and DARPA on the long term. Nor has their been a substantial effort to derive generic applications from work on spectfic hardware funded by NASA and DOD. These observations do not represent conclusions of a complete and formal study, but the views are fully supported by the visits to industrial organdzations carrled out in the course of this assessment.

\section{B. Industry Cooperation in Generic Research:}

Precedents for joint efforts are abundant. A recent and highly publicized example of cooperation 1n R\&D can be found in the Microelectronics Circuits Corporation, a not-for proflt organization, established in Austin, Texas to advance computer technology for a large group of subscribing companies that are 1 n competition with each other. Heat Transfer Research, Incorporated, a fortprofit company carries out R\&D and provides consultation for many subscribers who are in competition with each other. HTR has been in business for many years. There are many other examples of jointly funded R\&D. Questions of antitrust laws have to be considered in each case, but there are many examples of cooperative R\&D living with them. Expectations are for the legislative and judicial enviroment to become even more benign.

In both examples clted above, government augments 1ndustry fund1ng. Under these conditions no restriction or added burden is imposed on private industry since there has already been agreement to share the research. It is certalnly reasonable for the liquid lubricants and the technical ceramics industry to cooperate with each other and the government on the same basis to carry out the programs discussed in Section VI D.

Raw materials, formulation, and process parameters are relatívely easy to maintain as trade secrets; and these are probably the key elements of proprietary information in the production of lubricant additives and technical ceramics. Such information cannot be shared as a subject of cooperative R\&D. General techn1ca1 "knowhow", the product of generic research is in another category. Though also important in competition, it is very difficult to keep proprietary, especially in an era of high technology. Scientists and engineers are mobile; there is tnterchange in the technical literature and professional societies. Computer hardware and software, diagnostic methods and instrumentation, and theoretical understanding are widespread.

Thus it w111 be possible to distinguish which information can be the subject of cooperative R\&D, and which not. The gain in cooperation, if it is great enough, may well overcome the disadvantage of sharling information that will eventually be shared anyway. The purpose of cooperative research and development is to reduce the magnitude of the investment cost and hence the risk in technical innovation. Th1s edge may be vital tin the face of competitors who use cooperative research. Disadvantages of sharing appear to be negligible in comparison. Generic research relating laboratory characterization and testing to performance in the fleld, 1.e. the programs of Sectior VI D, are very ll adapted to cooperative R\&D.

ECUT management might manage a cooperative program with support from the National Laboratorles, contractor support, or both. The management would 
plan, procure, and manage a jolntly funded research program. Research would be carried out at universitles, or by speclallzed research organtzations. It would be the responsibility of the managers to find the best sources and then to Integrate the program to produce a result responsive to the cooperating industrial sponsors. These industrial sponsors would agree on the program beforehand, and commit funding for an extended period subject to continulng good performance by the research teams as detemined by perlodic reviews. Thus industry would join with ECUT in managing the generic research program.

Work1ng with industry in a cooperative program has three key advantages for ECUT. Firstly, since industry is investing its own resources, there is direct evidence of the Importance of the program. Secondly, the addition of resources provided by industry permit ECUT to develop a fully integrated generic research program on a limited budget. Elnally, cooperation by industry on a program to produce Information for tts own use will help to motivate greater effectiveness in the coordination and direction required to make the producer of research results responslve to the users needs. Discussions carried out in the course of this assessment indicate that Industry would welcome an inttiative fostering cooperation. ECUT support of such an initiative might be very fruitful. 
No. of

Copies

OFFSITE

12 T. Levinson

U.S. Oepartment of Energy Forrestal Building CE-142 Washington, D.C. 20585

J. J. Eberhardt

U.S. Oepartment of Energy Forrestal Building

Mail Stop 68025

Washington, 0.C. 20585

30 DOE Technical Information Center

\section{A. Anderson}

Multi-Arc Vacuum Systems Inc.

261 East 5th Avenue

St. Pau 1, MN 55101

C. Albertson

Borg-Warner Corporation

1200 South Wolf Road

Des Plaines, IL 60018

A. Becker

Alumina, Chem, \& Ceramics Division

Alcoa Research Laboratories

Alcoa Center, PA 15069

P. N. Blumberg

Integral Technologies, Inc.

415 East Plaza Drive

Westmont, IL 60559

L. J. Brombolich

Compu-Tec Engr. Inc.

300 Chesterfield Center, 205

Chesterfield, MO 63017

W. Bryzik

U.S. Army TACOM

AMSTA-RGR

Warren, MI 48090
No of

Copies

D. H. Buckley

NASA/Lewis Research Center

23-2

Cleveland, $\mathrm{OH} \quad 44135$

R. F. Bunshah

Oepartment of Materials Science

University of California at

Los Angeles

6532 Boelter Hall

Los Angeles, CA 90024

J. A. Carpenter, Jr.

Oak Ridge National Laboratory

P0 Box $x$, Building 4508

Oak Ridge, TN 37831

D. C. Classen

Caterpillar Tractor Co.

Mfg. Engr. Building $W$

600 West Washington Street

East Peoria, IL 61630

F. U. Carignan

Advanced Mechanical

Technology Inc.

141 California Street

Newt on, MA 02158

D. L. Cocke

Texas A\&M University

Department of Chemistry

College Station, TX 77843-3255

H. S. Cheng

Dept. of Mechanical Engineering

Center for Engineering

Tribology

Northwestern University

Evanston, IL 60201

G. W. Clark

Oak Ridge National Laboratory

PO Box $X$, Building 4508

Oak Ridge, TN 37831 
No of

Copies

G. Chang

29615 Lincoln Road

Bay Village, $\mathrm{OH} 44140$

M. J. Cronin

Mechanical Technology, Inc.

968 Albany-Shaker Road

Latham, NY 12110

J. L. Duda

Pennsylvania State University

133 Fenske Laboratory

University Park, PA 16802

S. K. Das

Materials Laboratory

Allied Corporation

P.0. Box $1021 \mathrm{R}$

Morristown, NJ 07960

J. F. Di\}l

Mechanical Technology Inc.

968 Albany-Shaker Road

Lathar, NY 12110

R. L. DaSilveira

Eutectic Corp.

4040172 nd Street

Flushing, NY 11358

C. A. Ebel

High Performance Ceramics

Norton Company

1 New Bond Street

Worcester, MA D1606

R. Erickson

Battelle-Columbus Laboratory

$505 \mathrm{King}$ Avenue

Columbus, OH 43201-2693

L. L. Fehrenbacher

2002 Huntwood Drive

Huntington Woods

Gambrills, MO 21054
No of

Copies

D. G. Flom

General Electric Company

Corporate R\&D, 4B4, K-1

P.0. Box 8

Schenectady, NY 12301

T. Fischer

Exxon Research

Clinton Township Route 22 East

Annandale, NJ 08801

P. Grayson

Eagle Picher Industries, Inc.

P.0. Box 1090

Miami, OK 74354

J. Graham

Deere and Company

Technical Center

3300 River Drive

Moline, IL 61265

S. Goguen

U.S. Department of Energy, CE 131

Mailstop 5E 043

Forrestal Building

1000 Independence Ave., SW

Washington, D.C. 20585

R. M. Gresham

$E / M$ Lubricants, Inc.

P.0. Box 220D, Highway 52 N.W.

West Lafayette, IN 47906

J. Horwath

Borg-Warner Corporation

Ingersoll Research Center

1200 S. Wolf Road

Des Plaines, IL 60018

S. M. Hsu

Room A257, Building 223

Inorganic Materials Division

National Bureau of Standards

Gaithersburg, MD 20899 
No of

Copies

N. S. Hakim (R03B)

Detroit Diesel Allison Division 36880 Ecorse Road

Romulus, MI 48174

C. R. Houska

Dept. of Materials Engineering

Virginia Polytechnic Institute

Blacksburg, VA 24061

R. A. Harmon

25 Schalren Drive

Latham, NY 12110

J. K. Hirvonen

Spire Corporation

Patriots Park

Bedford, MA 07130

10 M. Kaminsky

Argonne National Laboratory

9700 South Cass

Arconne, IL 60439

E. E. Klaus

Dept. of Chemical Engineering

Pernsylvania State University

University Park, PA 16802

R. Krutenat, 102/0217

Exxon Research and

Engineering $\mathrm{Co}$.

Florham Park, NJ 07932

S. Khanna

Solid State Science Research Group

Jet Propulsion Laboratory

4800 Oak Grove Drive

MS $122-123$

Pasadena, CA 91109

K. Ludema

University of Michigan

Dept. of Mechanical Engineering

2024 G. G. Brown

Ann Arbor, MI 48109-2125
No of

Copies

Librarian

Deere and Company

Technical Center

3300 River Orive

Moline, IL 61265-1792

F. F. Ling

Mechanical Engineering

Jonsson Engineering Center

Rensseiaer Polytechnic

Institute

Troy, NY 12181

H. LeKhac

DHR Inc.

6849 0ld Dominion Drive

McLean, VA 22101

H. E. McCormick

Director of Engineering

Ransey Piston Ring Division

TRW Automotive Products, Inc.

1233 Manchester Road

Manchester, MO 63011

C. Mecklenburg

AFWAL/MLBT

Wright Patterson AFB

Dayton, $0 \mathrm{H}$ 45433-6533

J. MCCOOl

SKF Industries

1100 First Avenue

King of Prussia, PA 19406

R. W. Meyerhoff

Union Carbide Corporation

Coatings Service

1500 Polco Street

Indianapolis, IN 46224

J. R. Mullaly

Pratt \& Whitney Aircraft

P.0. Box 2691

MS 707-28

West Palm Beach, FL 33402 
No of

Copies

P. Madden

SKF Industries

1100 First Avenue

King of Prussia, PA 19506

M. B. Peterson

Wear Sciences, Inc.

925 Mallard Circle

Arnold, MD 21012

0 . Pinkus

Mechanical Technology Inc.

968 Albany-Shaker Road

Latham, NY 12110

T. F. J. Quinn

Tribology and Rheology

Laboratory

School of Mechanical

Engineering

Georgia Institute of Technology

At lanta, GA 30332

R. C. Rosenberg

General Motors Research

Laboratory

Fluid Mechanics Department

Warren, MI 48090

D. A. Rigney

The Ohio State University

Dept. of Metallurgical

Engineering

141A Fontana Laboratories

116 West 19th Avenue

Columbus, DH 43210-1179

A. W. Ruff

National Bureau of Standards

Metallurgy Division

Room B266-Materials Building

Gaithersburg, MD 20899

W. D. Sproul

Borg-Warner Corporation

1200 South Wolf Road

Des Plaines, IL 60018
No of

Copies

P. Sutor

Midwest Research Institute

425 Volker Boulevard

Kansas City, MO 64110

40

L. B. Sibley

Tribology Consultants, Inc. 504 Foxwood Lane

Paoli, PA 19301

A. C. Schaffhauser

Oak Ridge National Laboratory

P.0. Box $X$

Oak Ridge, TN 37831

I. L. Singer

Naval Research Laboratory

Code 6170

Washington, D.C. 20375

G. L. Starr, Manager

MetalTurgical Engineering

Cummins Engine Technical Center

Box 3005

Columbus, in 47202-3005

R. Slone 50165

Cummins Engine Technical Center

Box 3305

Columbus, IN 47202-3005

T. C. Spalvins

NASA/Lewis Research Center

MS 23-2

Cleveland, $\mathrm{OH} \quad 44135$

M. Shaw

Arizona State University

ECG 247, Mechanical Engineering

Tempe, AZ 85287

P. Swanson

John Deere Company

Technical Center

3300 River Orive

Moline, IL. 61265 
No of

Copies

L. D. Wedeven

SKF Industries, Inc.

1100 First Avenue

King of Prussia, PA 19406

R. Ted Wimber

Deere and Company

Technical Center

3300 River Drive

Moline, IL 61265-2792

D. F. Wilcock, President

Tribolock, Inc.

1949 Hexham Road

Schenectady, NY $1230 \mathrm{~g}$

W. 0 . Winer

Tribology and Rheology Laboratory

School of Mechanical

Engineering

Gecrgia Institute of Technology

At lanta, GA 30332

D. Kuhlman-Wilsdorf

University of Virginia

Physics Department

Mc Cormick Road

Chòrlottesville, VA 22901

W. H. Winnard

Battel?e Memorial Institute

$20 \approx 0$ M. Street NW

Washington, D.C. 20036

C. S. Yust

Metals and Ceramics Division

Oak Ridge National Laboratory

P.0. Box $X$

Dak Ridge, TN 37831

T. M. Yonushonis

Cummins Engine

Mail Code 50183, Box 3005

Columbus, IN 47202-3005
No of

Copies

M. Zlotnick

141 East 88th Street

New York, NY 10028

C. A. Zanis

Department of the Navy

Naval Sea Systems Command

Research and Development Office

Washington, D.C. 20362

FOREIGN COUNTRIES

Dr. Jochen P. Biersack
Hahn-Meitner-Institut
Glienicker Strabe 100
1000 Berlin 39
West Germany

Dr. Erich Bergmann

Balzers Aktiengesellschaft

FL-9496 Balzers

Furstentum, Liechtenstein

Professor Dr. H. Czichos

Federal Institute for Materials

Research and Testing

Unter den Eichen 87

D-1000 Berlin 45

West Germany

Dr. Geoff Dearnaley

Nuclear Physics Division

Building $\mathrm{H} 8$

AERE Harwell

Didcot, Oxfordshire

United Kingdom OX 11 ORA

Dr. Hans E. Hintermann

Laboratoire Suisse de

Recherches Horlogeves

$\mathrm{CH}-2000$ Neuchatel

Switzerland 
No of

Copies

Dr. Richard Horton, Manager Energy Conservation Technology Centre

Engineering Sciences Division

B15l Harwe11 Laboratory

oxfordshire 0x ll ORA

England

Dr. Boris Navinsek

Jozef Stefan Institute

61001 Ljubljana

Jamova 39

Yugoslavia

Prof. Dr. ir. J. Roos

Katholieke Universiteit Leuven

Department Metaalkunde

de Croylaan 2

B-3030 Leuven (Heverlee)

Belgium

Dr. S. Veprek

Anorganisch-Chemisches

Institut der Universitat Zurich

winterthurerstrasse 190

8057 Zurich

Switzerland
No. of

Copies

ONSITE

DOE Richland Operations Office

H. E. Ransom

12 Pacific Northwest Laboratory

D. L. Brenchley

C. H. Imhoff

D. C. Kuick

J. A. Russe11

M. T. Thomas

Publishing Coordination MH (2)

Technical Information (5) 